\title{
(In)definiteness Spread in Semitic Construct State: Does it Really Exist?*
}

Mohammed Q. Shormani (Ibb)

\begin{abstract}
To argue against a long established assumption seems to be not that easy task. In this article, I argue against one of those assumptions, namely (in)definiteness spread in Semitic Construct State (CS). I argue that CSs are of two types: either definite or indefinite. The former refers to those CSs, where the head $\mathrm{N}$ is syntactically definite, in the sense of having the definite article al-/ha- (the, Arabic/Hebrew), and the latter to those not having it. Three tenets constitute the crux of this paper: i) the controversy (in)definiteness spread gives rise to among Semitic scholars, ii) there does exist good evidence that the head $\mathrm{N}$ of CSs can take the definite article in Arabic and Hebrew, and iii) in Arabic the absence of the indefinite article (marker) - $n$ on the head $\mathrm{N}$ has presumably to do with what I call VCR (= the Vowel Contextualization Rule) like several similar other phonological phenomena in the language. As for the specificity/uniqueness denoted by the head $\mathrm{N}$ of a CS in some contexts, I propose that such specificity has nothing to do with definiteness spread, but rather it may be linked to a Universal Grammar (UG) principle, which correlates specificity/uniqueness with possessivization crosslinguistically, or to a UG parameter in the case of Semitic CSs.
\end{abstract}

\section{Introduction}

A Construct State (CS) like (1) below is a DP construction in Semitic languages. One of the properties of CSs is the (in)definiteness spread, where (in)definiteness is claimed to spread from the genitive DP complement (GDC) to the head N, and then to the whole construct. However, (in)definiteness spread is one of the most controversial issues in the generative syntax of Semitic up to date. Perhaps, no other issue in the study of Semitic (and even Romanian) CSs is more controversial than accounting for (in)definiteness spread. Some linguists (see Borer 1999; Shlonsky 2004; Alshara'i 2014; Alanbari 1997; Dobrovie-Sorin 2001, 2003; Sichel 2002, 2003; among many others) argue that there is no (in)definiteness spread in CSs.

\footnotetext{
* I would like to thank Gabi Danon and Elizabeth Ritter for their valuable and helpful discussion on previous drafts of this paper. I would also like to thank two anonymous reviewers of $L O$ for their insightful comments. Whatever errors remaining are mine alone.

The following abbreviations are used throughout this article. Acc $=$ Accusative, AGR $=$ agreement, $\mathrm{C}=$ Complementizer,$\quad$ Card $=$ Cardinal,$\quad$ Def $=$ definiteness,$\quad$ Dem $=$ demonstrative, $\mathrm{DL}=$ dual, $\mathrm{F}=$ feminine , Gen $=$ Genitive,$I=$ Inflection, $L i t=$ literally,$M=$ masculine, Nom $=$ Nominative, Num = Number, $P L=$ plural, $\mathrm{pt}=$ past, $\mathrm{SG}=$ Singular, $\mathrm{T}=$ tense, $\mathrm{V}=\mathrm{Verb}$. Those abbreviations and acronyms that are not mentioned here are indicated in the first use.
}

Linguistik online 80, 1/17 - http://dx.doi.org/10.13092/lo.80.3568

CC by 3.0 
Some others (see Danon 2006; Siloni 2001; Fassi Fehri 1993, 1999; Kremers 2003; Longobardi 1994, 1996, 2001; among many others) argue that it takes place in some CSs but not in some others. Several proposals, therefore, have emerged to account for (in)definiteness spread existence or the otherwise. Some of these approaches are based on morpho-syntax (see e. g. Borer 1988, 1996, 1999; Benmamoun 2000, 2003), some are based on syntax (see e. g. Shlonsky 2004; Ritter 1991; Fassi Fehri 1999; Danon 2001, 2002a/b; Pereltsvaig 2006) and some others on semantics (see e. g. Dobrovie-Sorin 2001, 2003; Heller 2002; Danon 2008; Siloni 2001, 2003). The diversity of the approaches devoted to analyzing (in)definiteness spread makes it clear that the subject matter involved is not that easy, and that there is more disagreement among scholars than consensus. (In)definiteness spread, thus, imposes several and serious challenges theoretically and empirically. As Danon (2008) puts it, (in)definiteness spread requires a mechanism in which more than one interpretation is needed for a single linguistic resource.

$\begin{array}{lll}\text { a) } & \text { bayt-u 1-mudarris-i } & \text { 1-kabiir-u } \\ \text { house-NOM the-teacher-GEN } & \text { the-big-NOM } \\ \text { 'The teacher's big house' } & \\ \text { b. } \begin{array}{l}\text { bayt-u mudarris-in } \\ \text { house-NOM teacher-GEN }\end{array} & \begin{array}{l}\text { kabiir-un } \\ \text { big-NOM }\end{array} \\ \text { 'A teacher's big house' } & \end{array}$

In (1a), it is claimed that the head $\mathrm{N}$ bayt-u, though without the definite article al-, is definite. It acquires/inherits its definiteness from its GDC, namely l-mudarris-i. In (1b), however, bayt$u$, though, again without the indefinite article (marker) $-n$, is said to be indefinite, because its GDC, viz. mudarris- $i$ is indefinite. In both cases, the evidence Semitic scholars provided is that the AP modifier kabiir-u (big) is definite in the former but indefinite in the latter. This claim is based on the assumption that AP modifiers in Semitic agree with the head Ns they modify in all features (Case, (in)definiteness and $\phi$-features). The assumption that the head $\mathrm{N}$ depends crucially in its (in)definiteness on its GDC leads several scholars to hold that the head $\mathrm{N}$ of a construct is bare.

However, controversy dominates the scene: some authors (see e. g. Heller 2002; DobrovieSorin 2001, 2003; Borer 1988, 1996, 1999; Shlonsky 2004; Alshara'i 2014; Alanbari 1997; Sichel 2002, 2003; Ritter 1988, 1991; Mohammad 1988, 1999; Ouhalla 2009) argue that there is no (in)definiteness spread, and some others (see Danon 2006, 2008; Siloni 2001, 2003; Fassi Fehri 1999; Benmamoun 2000, 2003; among others) argue that it takes place in some CSs while in some others it does not. In this paper, I argue against (in)definiteness spread in Semitic CSs, focusing mainly on Arabic and Hebrew and supporting my views with facts from both languages. 
The paper proceeds as follows. In section 2, I briefly discuss three approaches that have tackled CSs in Arabic and Hebrew, namely prosody, head movement and semantic approaches. I also discuss how these approaches account for (in)definiteness spread, arguing that none of them was uncontroversial. In section 3, I tackle the way (in)definiteness is interpreted. In section 4, I embody the controversy held among Semiticits in relation to (in)definiteness spread, examining the several and different views regarding it. I propose that there is no (in)definiteness spread in Sematic CSs, providing examples from both languages to support my proposal. In section 5, I discuss how definiteness is related to uniqueness, arguing that uniqueness/specificity as a feature of possessivization could be linked to a Universal Grammar (UG) principle/parameter, and section 6 concludes the paper.

\section{2 (In)definiteness spread: several approaches}

As alluded to above, several approaches, viz. prosodic, morpho-syntactic, syntactic and semantic, among others, have emerged which tried to account for (in)definiteness spread in Smeitic. These approaches relate (in)definiteness spread to other properties of CS in general such as "its word-like properties, the ungrammaticality of attaching the definite article to the head of a construct, and the word order" among other properties (Danon 2008: 887). I briefly touch on some of these approaches in what follows.

\subsection{Prosody}

Prosody is a morpho-phonological approach, the very idea of making use of which comes from considering the CS one word. However, I will not discuss the CS properties from a prosodic point of view. I will just focus on how prosody has accounted for (in)definiteness spread in Semitic CSs. For instance, based on prosody, Benmamoun $(2000,2003)$ argues that it is not surprising that (in)definiteness spread takes place in CSs, because both the head $\mathrm{N}$ and its GDC constitute one word. However, Benmamoun (and I assume all prosody proponents) tackles only (in)definiteness spread as a property of CSs, but ignores other properties specific to such structures. As for Hebrew, Borer (1999), for instance, argues that the head $\mathrm{N}$ has to have the $[ \pm$ Def] feature by being incorporated in another noun, namely its GDC. Borer (1999) argues that the head N of a CS is unspecified for both definiteness and indefiniteness. Along these lines Danon (2008: 892) argues that the head N does not have [ \pm Def] which explicitly states that the head $\mathrm{N}$ "cannot, by itself, determine the definiteness value of the DP which serves as its extended projection". Borer (1999) also argues that the head N acquires its (in)definiteness only by raising to D, where it gets its [ \pm Def]. Following Borer (1999) in this aspect, Danon (2008) argues that this does not always hold particularly in event CS nominals. 
In prosody, for (in)definiteness spread to take place, Borer (1999) claims that the GDC has to move to Spec-NumP. Consequently, she claims that this incorporation accounts not only for (in)definiteness spread but also for the CS as a prosodic unit and its word-like properties. In Borer's analysis, it is the incorporation of the GDC into the head of the CS what results in the spread of (in)definiteness, first to the head N, and then to the whole CS. Borer claims that following phrasal movement and head incorporation, a consequence of such a feature, a percolation operation takes place. She also claims that there is some kind of association, whereby the definiteness or indefiniteness of the head $\mathrm{N}$ is associated with that of the GDC. Due to this association, she argues, the whole CS becomes associated with the definiteness or indefiniteness of the GDC. However, Borer ascribes the (in)definiteness of the head $\mathrm{N}$ acquired from its GDC to the phonological boundary between the head N and its GDC. In short, almost all prosody proponents (see e. g. Borer 1999; Siloni 2001, 2003; Benmamoun 2000, 2003) argue that CSs have word-like properties, claiming that CSs constitute a prosodic unit at PF.

However, prosody, in fact, leaves open several questions. One of the critical points is what Gebregziabher (2013) calls the non-incorporation into D, which results in non-(in)definiteness spread. Gebregziabher argues that if (in)definiteness is licensed/assigned in the Spec-NumP, and since this Spec-NumP is governed by D, that is above it, no incorporation into D will result in supplying the head $\mathrm{N}$ with [+ Def] or [- Def]. In addition, prosody fails to account for coordinated CSs and violates "Coordinate Structure Constraint" (for more on this, see Doron/Meir 2013, see also Shormani 2016).

Another aspect for which prosody has been criticized is that adjacency between the head $\mathrm{N}$ and its GDC does not always hold. For one thing, there is good evidence that an AP modifier can intervene between the head $\mathrm{N}$ and its GDC, which, in fact, prevents (in)definiteness spread to take place. For instance, in relation to Spanish Arabic, Ouhalla (2009) points out that prosody in this variety of Arabic is not consistent in the reported data from Corriente (1997). This is illustrated in (2a), where the AP modifier can intervene between the head $\mathrm{N}$ and its GDC, on the one hand, and the definite article al-can be attached to the head N, on the other hand. Ouhalla argues that "the possessor fails to raise to Spec,Num along the lines roughly shown" Ouhalla (2009: 329) and schematized in (2b). ${ }^{1}$

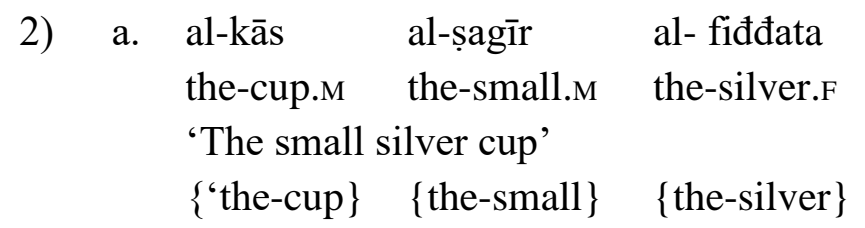

b. $\quad[\mathrm{DP}$ the-[N cup] [NumP ... [NP [DP the-small] [NP [DP the-silver] [N' ...

\footnotetext{
${ }^{1}$ Additional support for this claim comes from Yemeni Arabic (YA). Consider (i) which is very productive in the language.

(i) al-şahn 1-kabiir 1-zijaaj

the-dish the-big the-glass

'The big dish made of glass'

In (i), the fact that the AP modifier l-kabiir occurs between the head $\mathrm{N}$ and its GDC also provides strong support for the fact that the head N and the GDC can be separated from each other. Along these lines, Shlonsky (2004: 1475) challenges the validity of incorporation approach. He rightly observes that "[ $[\mathrm{t}] \mathrm{he} \mathrm{N} \rightarrow \mathrm{D}$ incorporation theory is thus not only vitiated by theory-internal considerations but invalidated by the absence of string adjacency between the two heads".
} 
Examples like (2a), indeed, cast some doubts not only on the way (in)definiteness spread is dealt with in the prosody framework, but also on the way CSs in general are handled. As is clear, the definite article al- is attached to the head $\mathrm{N}$ al-kās ('the cup'), and the AP modifier al-sagir (the small) intervenes between the head N and its GDC al-fidda ('the silver'). In addition, Danon (2008: 892-894) notes a number of drawbacks in Borer's analysis: i) the assumption that the embedded nominal raises to Spec-NumP, as a factor making the incorporation structurally possible, is a stipulation that does not follow from anything else, ii) the assumption that all DPs must carry a definiteness feature is also stipulative. While Borer (1999) relates the presence of $[ \pm$ Def] to referentiality, this is not enough to rule out nominals with no [ \pm Def] specification, i. e. there is no obvious reason why nominals lacking this feature could not be generated, perhaps being interpreted as indefinite, using an operation of existential closure, iii) the fact that non-referential CSs in predicate positions display exactly the same syntactic properties as referential ones makes it doubtful that Borer's Definiteness Criterion can be independently motivated, and iv) in case that both kinds of feature percolation do exist as part of UG, judging whether this analysis involves construction specific operations or not depends on having a full theory of feature sharing and percolation operations across languages.

Now, if the features of the head $\mathrm{N}$ depend on those of the GDC, the question is why is it that (in)definiteness spread is the only feature that is shared by both members of the CS and nothing else? Put differently, why other features like Case or $\phi$-features (number, person and gender), or even any of them, for instance, is not spread. Along these lines, Benmamoun (2000, 2003) questions this issue but he finds himself unable to account for why (at least) number is not spread in CSs. The proponents of prosody have tried to make a connection between (in)definiteness spread and other properties based on the word status of the CS. However, as noted by Danon (2008), it is not obvious which of these properties are much related to (in)definiteness spread and which are not. If a CS is a word, it, then, follows that nothing can intervene between the head N and its GDC, and this leads to considering (2) above ungrammatical, which is definitely not.

There is also good evidence supporting examples in (2) from Standard/Classical Arabic, where a CS head N can be separated from its GDC by a constituent of different syntactic categories. Consider (3), where the adverb yawm-an intervenes between the head naahit-i and the GDC saxrat-in. ${ }^{2}$

$\begin{array}{lll}\text { ka-naahit-i yawm-an } & \text { şaxrat-in } \\ \text { as-graver-GEN } & \text { day-ACC } & \text { rock-GEN } \\ \text { 'As a graver graving a rock one day' }\end{array}$

(3) provides us with strong support against the claim that the head N and its GDC constitute a word. Consider also (4) from Classical Arabic (=CA) (i. e. Qur'an, Hadith and others). For

\footnotetext{
2 Another example showing the separation between the head N and its GDC is presented in (i).

(i) "flaa tahsaban Pallah-a muxlifa waSd-a-hu rusul-i-hi" (Qur'an) no think Allah-ACC failing promise-ACC-his messengers-GEN-his 'Do not think that Allah will fail the promise given to his messengers.'

In (i), the waSd-a-hu intervenes between the head N muxlifa and the GDC rusul-i-hi.
} 
instance, in (4a), Pawlaad-a-hum ('their boys') intervenes between the head N qatl-u ('killing') and its GDC šurkaa?-i-him ('their partners') (from Ibn Jinni’s Alxaşaaiş: I-219-220). ${ }^{3}$
4)
a. "qatl-u
killing-NOM
boys-ACC.their
b. "...taarik-u 1-i-şaahib-i"
leaving to-me-friend-my
'Leaving my friend to me'
Pawlaad-a-hum šurkaa?-i-him"
(Qur'an) $)^{4}$
partners-GEN-their
'Their partners' killing of their children'
c. haaðaa $\quad$ ulaam-u
[wallahi] zaid-in
This boy-NOM
[swear by Allah] Zaid-GEN
'I swear by Allah that this is Zaid's boy.'

It turns out, then, that adjacency between the head $\mathrm{N}$ and its GDC does not always hold. This clearly casts doubts on the validity of (in)definiteness spread phenomena. ${ }^{5}$

\subsection{Head movement}

Head movement (known in the nominal domain as $\mathrm{N}^{0}$-to- $\mathrm{D}^{0}$ approach) has been one of the approaches to analyzing CS properties including (in)definiteness spread (though peripherally, see Ritter 1991; Fassi Fehri 1993, 1999; Longobardi 1994, 1996; Siloni 1997; among many others). As for Arabic, following Ritter (1991), Fassi Fehri (1999) proposes that (in)definiteness spread is best handled in head movement approach. He argues that (in)definiteness spread is assigned/licensed/checked in the Spec-head configuration with D, because by moving to D, the head N "inherits" the [ \pm Def] of the GDC in the Spec-DP. As for Hebrew, Ritter (1991) tries to link (in)definiteness spread to other properties (like word order) and proposes that the head $\mathrm{N}$ acquires its (in)definiteness spread from its GDC in a Spec-head configuration with D. She also proposes that the null D assigns Gen Case to the head $\mathrm{N}$ but only when it is given "phonetic content" by its movement to it, and hence being able to assign Case. Ritter (1991) sees (in)definiteness spread as a feature agreement process. In this process, the head of the DP, i. e. the null $D_{\text {gen }}$ acquires (in)definiteness spread from its GDC in a Spec-head relation. In other words, Ritter (1991) argues that neither $\mathrm{D}_{\text {gen }}$ nor its GDC is inherently specified for (in)definiteness spread feature, but the head $\mathrm{N}$ inherits the $[ \pm$ Def] value

\footnotetext{
3 This, in fact, has been agreed upon in the two linguistic schools of traditional Arabic grammarians (known as Kofa and Basra) that adjacency does not always hold (see also Wright 1898; Al-Anbārī 1997; Alshara'i 2014; Al-Aboudi 1985).

${ }^{4}$ An anonymous reviewer points out that the example in (4a) has another reading in the Holy Qur'an. However, this example has been cited according to the reading of Ibn Saamir (see also Al-Sywti HHGG, II; Al-Aboudi 1985).

${ }^{5}$ In addition, it is difficult to postulate that prosody could account for the properties of multi-embedded CSs (those having more than one head N and more than one GDC). Multi-embedded CSs in Arabic include ones like (i, from Shormani 2016: 30).
(i) bayt-u ibn-i haars-i bawaabat-i 1-maadrasat-i house-NOM son-GEN guard-GEN gate-GEN the-school-GEN

'A house of a son of a guard of a gate of the school'

(i) represents a multi-embedded CS, which has four head Ns and four GDCs. For a comprehensive discussion on Multi-embedded (and Complex CSs), I refer the reader to Shormani (2016). Shormani (2016) proposes that phase approach is more adquate to the analysis and derivation of multi-embedded CSs than any other previous approach.
} 
from its GDC, which is base-generated in its Spec, and by moving to D, the head $\mathrm{N}$ assigns the same value to $\mathrm{D}$ and consequently to the whole CS. She proposes NumP (= Number Phrase) as an intermediate functional projection (positioned higher than $\mathrm{N}$ but lower than $\mathrm{D}$ ) and that number feature is base-generated in Num. She proposes that the head $\mathrm{N}$ raises to Num prior to raising to D. Many researchers agree with her proposal that head movement takes place in the derivation, however, they do not (to some extent) agree with her proposal regarding (in)definiteness spread (see Danon 2001, 2008; Fassi Fehri 1999; Engelhardt 2000; Wintner 2000; Borer 1996, 1999; Siloni 2001, 2003; among other related work).

Since the proposals put forth by Ritter, they have undergone several modifications by a considerable number of researchers, though each has modified it differently form the other(s). Fassi Fehri (1999), for instance, argues for a "split DP", where D is split into two distinct head Ds. The GDC, Fassi Fehri argues, is attracted by the lower D to its Spec, where it checks its unspecified (in)definiteness spread feature. He, then, argues that (in)definiteness spread is derived via Spec-head agreement, arguing that a later N-to-D (a movement to the higher one) is motivated by the checking of Case feature. This "later N-to-D", Fassi Fehri argues, results in the (in)definiteness of the whole CS. Another example of such modification is found in Cinque (2003, 2005) who argues against N-to-D movement in analyzing CSs. Cinque argues for remnant (phrasal) movement, where the head N (as part of XP, here NP) targets Spec-DP and not D, suggesting that (in)definiteness spread may be accounted for in terms of feature sharing which simultaneously takes place under Spec-head configuration with Gen Case checking (see also Shlonsky 2004). Siloni (1997) proposes an intermediate AgrP projection in the Spec of which (in)definiteness spread takes place simultaneously with Case assignment. This is followed by a movement of the head $\mathrm{N}$ along with Agr to D which is motivated by feature checking as well.

However, head movement, and specifically agreement mechanism for accounting for (in)definiteness spread, has been challenged. For instance, Dobrovie-Sorin (2001) maintains that agreement does not allow a feature to be realized once and interpreted twice. Agreement, Dobrovie-Sorin argues, allows a feature to be realized twice and interpreted once (see also Danon 2008). Some Hebrew scholars (see e. g. Engelhardt 2000; Wintner 2000) argue that the real problem imposed by head movement is positing $\mathrm{D}$ as a $\mathrm{D}$, because in Hebrew no evidence for such a category is entertained, specifically when accounting for indefiniteness spread (Hebrew has no indefinite article). As for definiteness spread, they consider $h a-$ a prefix (inflection) and not a word, and hence it just triggers agreement between the head $\mathrm{N}$ of a CS and its AP modifier(s) but not between the head N and its (in)definite GDC. ${ }^{6}$

As far as minimalism is concerned, Danon (2008) proposes a feature sharing mechanism instead of a feature checking/valuation-and-deletion one. He argues that feature sharing, though theoretically simple, elegantly accounts for the full range of semantic facts in general and (in)definiteness spread in particular. In Danon's analysis, (in)definiteness spread is accounted for in terms of relating nodes having the same unvalued features (though not in the same ccommand domain) which form a "permanent link". When one of these nodes enters an Agree

\footnotetext{
${ }^{6}$ See also (Mahajan 2003; Pereltsvaig 2006; Shlonsky 2004; among other related work) who argue against head movement, and see in particular Chomsky (2007: 26) who argues against $\mathrm{D}^{\circ}$ as the assumed landing site which the head $\mathrm{N}$ is supposed to raise to.
} 
relation with another having the same feature, but valued, Agree then does not value only the unvalued node but also all the nodes in the link. In this feature sharing mechanism, Danon argues, agreement in (in)definiteness between the head N and its AP modifier(s) takes place simultaneously with other features, say, $\phi$-features, for instance.

\subsection{Semantic approaches}

Walking through the above discussion (though briefly), it is clear that disagreement among researchers in accounting for (in)definiteness spread is much more than consensus. Every approach employed comes up with several problems. For this reason (among others), some authors seek some alternative mechanisms that could account for (in)definiteness spread adequately. They have looked at semantics and how it could be adopted in such a phenomenon. Semantic approaches stem from the idea that there is no (in)definiteness spread. DobrovieSorin (2003), for instance, argues that semantics seems to be more adequate than syntax in accounting for the apparently assumed (in)definiteness spread, not only in Semitics but also in languages that have preposition-less genitives such as Romanian. She argues that there is some kind of semantic composition involved in the interpretation of CSs. She, thus, proposes that there is a function from individuals to individuals which is manifested by the head $\mathrm{N}$. Lexical specification, she argues, determines the content of such a function as in the case of relational nouns like mother (see also Danon 2008). She adds that the content of the function can also be determined by context. A function can simply be defined as a mapping relation, which, uniquely, denotes an individual. If a function is applied to the denotation of a definite DP, it gives another unique individual. However, the DP under consideration has to be unique in the given context, and this makes the uniqueness presupposition of (in)definiteness spread to the whole construct. Consider (5), where a function of the type $(<\mathrm{e}, \mathrm{e}>)$, denoted by the head $\mathrm{N}$, denotes a function from individuals to individuals.

5)
a. bayt-u
1-mudarris-i
house-NOM the-teacher-GEN
Lit: 'house the teacher'

b. bayt-u l-mudarris- $i$ : $f(\mathrm{x})$, where $f=$ house-of and $\mathrm{x}=$ [the teacher]

According to Dobrovie-Sorin, there are two factors that constitute the definiteness of the CS in (5): i) the GDC l-mudarris-i, is syntactically and semantically definite, and thus, presupposes uniqueness, and ii) the head $\mathrm{N}$ bayt- $u$ denotes a function from individuals to individuals, and hence its application to each individual gives another unique individual. Based on this analysis, Dobrovie-Sorin argues that there is no syntactic mechanism required to explain the apparent definiteness spread. She maintains that definiteness spread in Saxon genitives and Semitic CSs is related to a universal semantic rule which is that the head $\mathrm{N}$ denotes a function of type $(<\mathrm{e}, \mathrm{e}>)$. This rule applies to the individual denoted by a DP in Spec-DP of another DP, and yields the individual denoted by the GDC. To her, there is no need for the postulation of some marked and construction-specific mechanism of Spec-Head agreement in [ \pm Def] features between the GDC and D of the head N. However, she confines this process to only definite CSs, because, she argues, indefinite CSs cannot be interpreted using this functionapplication mechanism. She argues that there is no uniqueness to be entailed by indefinite CSs. She concludes thus that indefinite CSs cannot be analyzed employing the type $(<\mathrm{e}, \mathrm{e}>)$ 
and require another mechanism of semantic composition as they are different structures from definite ones.

Along the stipulations of Dobrovie-Sorin (2003), Heller (2002) argues that being morphophonologically distinct from the base form of the noun, the head $\mathrm{N}$ in a Semitic CS denotes a function from individuals to individuals (i. e. $<$ e, e $>$ ), which takes the GDC as an argument. She argues that the CS's denotation as an entire complex is the uniqueness of the individual. This uniqueness is the value of the function for the individual which is denoted by the GDC. She also argues that the semantic content of the function is confined to lexical but not contextual relations. However, Heller seems to distinguish between singular and plural head Ns. She makes it clear, based on the functional nature of the head $\mathrm{N}$, that when the head $\mathrm{N}$ is plural the entire CS will denote a unique individual which is not necessarily tied to the nature of the GDC. These stipulations were actually based on predictions where uniqueness is not dictated by world knowledge and thus must be due to the construction itself.

Though semantic approaches to (in)definiteness spread seem to some extent to be on the right track, they are not without shortcomings. As noted by Danon (2008), they leave open many aspects and properties of CSs unaccounted for. For instance, they do not account for the presence of et preceding definite objects in Hebrew, and why the AP modifying a CS must be definite if the modified CS has a definite GDC. Another shortcoming, noted by Danon (2008), is that semantic approaches interpret double definiteness (i. e. where both members of the construct are definite, hence the whole CS), but they neglect some other properties such as definiteness on the GDC, but not on the head N, no definiteness interpretation at all, etc. (see also Falk 2006).

\section{3 (In)definiteness interpretation}

In this section, I argue that though context is 'fed' by syntax, (in)definiteness spread does not always hold. As could be inferred from our analysis above, scholars hypothesize (in)definiteness spread due mainly to interpretation, whereby the head $\mathrm{N}$ of a CS is interpreted as (in)definite depending on the syntactic (in)definiteness of the GDC. I show here how (in)definiteness spread has been interpreted in the previous analyses of Semitic CSs, arguing that it is only the context which plays the major role in such interpretation in both spheres, i. e. definite and indefinite. For instance, in Arabic the (in)definiteness spread has been related to morpho-syntactic features on the heads N and D. Fassi Fehri (1999: 146) argues that definiteness spread/definiteness inheritance "takes place in Spec AGR, but its effect is carried on to $\mathrm{N}$ by stipulating that Gen can only be checked if AGR Gen" raises to D. He also suggests that since the head $\mathrm{N}$ moves to $\mathrm{D}$, it inherits the definiteness feature from the head $\mathrm{N}$ in Spec-head agreement, manifested by the agreement between the head $\mathrm{N}$ and its AP modifier(s). In Hebrew, (in)definiteness spread has to some extent been interpreted along the same lines. However, (in)definiteness spread interpretation in Hebrew differs from that of Arabic in the absence or presence of et (the so-called object marker [OM]). ${ }^{7}$ Danon (2008), for instance, argues that examples like (6) are interpreted as definite.

\footnotetext{
${ }^{7}$ There is a controversy regarding what $e t$ is. Some scholars see that it is OM (e. g. Pereltsvaig 2006, 2007), some others (e. g. Danon 2002a/b) argue that it is an Acc Case assigner, and some others maintain that it is a preposition (see e. g. Shlonsky 2004).
} 


6) ha-mištara ivtexa et hafganat ha-studentim ha-gdola
the-police secured OM demonstration the-students the-big
'The police secured the big student demonstration.'

Danon (2008) argues that this is due to the presence of et before hafganat, i. e. the head $\mathrm{N}$ of the CS, and the definite AP modifier ha-gdola. The same thing could also be found in Arabic as in (1a) above reproduced here as (7) for convenience.
7) bayt-u
1-mudarris-i
l-kabiir-u
house-NOM the-teacher-GEN
the-big-NOM
'The teacher's big house'

The same thing can be said about indefinite CSs (i. e. where GDC is indefinite) as in (8):
8) ha-mištara ivtexa hafganat studentim gdola
the-police secured demonstration students big
'The police secured a big student demonstration.'

where the absence of et before the head $\mathrm{N}$ and the absence of $h a$ - on both the AP and the GDC renders the whole CS indefinite, i. e. it is interpreted as indefinite. The same thing can be said of the Arabic example in (1b) reproduced as (9) for convenience.
9) bayt-u mudarris-in kabiir-un
house-NOM teacher-GEN big-NOM
'A teacher's big house'

However, examples like (9) call into question the fact that interpreting the construct as definite or indefinite is more related to the (in)definiteness of the GDC per se, which is exactly what we mean by (in)definiteness spread. This is what analyses in the literature claim. However, in some contexts even if the GDC is syntactically and semantically definite as in (10), the construct is interpreted as indefinite (cf. Danon 2001, 2002b; Fassi Fehri 1999).
10) suriqa kitaab-u l-walad- $i$
was-stolen book-NOM the-boy-GEN
'A book belonging to the boy was stolen.'

Here, it seems untenable to say that the head $\mathrm{N}$ kitaab- $u$ is definite/specific though the GDC $l$ walad- $i$ is definite. Put differently, it is clear that there is no specific book we are talking about, i. e. there is not a specific answer to a question such as: which of the student's books was stolen? Another example is (11), where specificity of r-rajul-a is not expected, though being syntactically definite, i. e. al- is attached to it.
11) Puhib-u r-rajul-a 1-kaamil-i 1-Pawsaaf-i
love-I the-man-ACC the-perfect-GEN the-features-GEN
'I love the perfect-featured man.'

However, the difference between (10) and (11) is that while in the former the GDC is a definite DP, $l$-walad-i, it is an adjectival construct state (ACS) in the latter, namely l-kaamil-i $l$ Pawsaaf-i (Lit: 'the-perfect the-features'). As it turns out, then, what matters most in the notion (in)definiteness spread is interpretation rather than syntactic and/or semantic (in)definiteness. 


\section{4 (In)definiteness of the head $\mathbf{N}$}

If our analysis so far is true, i. e. if the head $\mathrm{N}$ is either definite or indefinite, it follows that the head $\mathrm{N}$ in Semitic CSs can take the (in)definite article, ruling out the possibility of bareness as a characteristic of the head N. Section 4.1 elaborates on Arabic, and section 4.2 discusses Hebrew.

\subsection{Arabic CSs}

If bareness of a noun is taken to mean that this noun appears without either the definite or indefinite article, then it seems that the head $\mathrm{N}$ is not bare as was assumed by the previous studies as illustrated by the simple DP in (12c).

12) a. al-bayt-u

the-house-NOM

'The house'

b. bayt-u-n

house-NOM-INDEF

'A house'

c. *bayt-u

house-NOM

d. *al-bayt-u-n

the-house-NOM-INDEF

In (12a), the head $\mathrm{N}$ al-byat- $u$ occurs with the definite article al-. In (12b), it occurs with the indefinite article $-n$. However, the ungrammaticality of (12c) indicates that bareness cannot be maintained. ${ }^{8}$ There seems to be a $[ \pm$ Def] feature underlying the ungrammaticality of $(12 \mathrm{c})$. Further, the ungrammaticality of (12d) indicates that both al- and $-n$ are in complementary distribution, which means that the head $\mathrm{N}$ of a simple DP has to be a full DP, i. e. either definite or indefinite.

\subsubsection{CS head Ns with al-}

In this section, I argue that the head $\mathrm{N}$ of an Arabic CS can take the definite article al- as in (13) representing CSs where the head $\mathrm{N}$ is definite and the GDC is indefinite.
13) al-mutqin-u
1-waajib-i
muhtaram-un jidd-an
the-well-performer-NOM the-duty-GeN respectable very-ACC
'The well-performer of the duty is very respectable.'

In (13), the head $\mathrm{N}$ al-mutqin- $u$ ('the well-performer') is definite, i. e. the definite article $a l$ - is prefixed to it, and the CS is well-formed, but consider (14).

\footnotetext{
${ }^{8}$ This is also further evidence that the morpheme $-n$ is an indefinite marker, see also Alshara'i (2014) for few contexts where $-n$ is not considered an indefinite marker.
} 


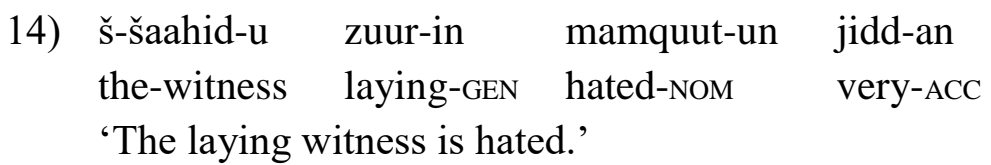

Unlike (13), in (14) the head $\mathrm{N}$ is definite while the GDC is indefinite. If we assume, as claimed in the literature, that the definiteness spread exists, the head $\mathrm{N}$ in (13) cannot have alattached to it, and likewise, if indefiniteness spread exists, the head $\mathrm{N}$ in (14) must be indefinite.

The definite article al- can also co-occur with duals and plurals as in (15a) and (15b), respectively.

15)
a. Al-mutqin-aa
1-waajib-i
muhtaram-aani
jidd-an
the-well-performer-NOM.DL the-duty-GEN
respectable-NOM.DL very-ACC
'The two well-performers of their duties are very respectable.'
b. al-mutqin-uu l-waajib-i muћtaram-uuna jidd-an
the-well-performer-NOM.PL the-duty-GEN.PL respectable-NOM.PL very-ACC
'The well-performers of their duties are very respectable.'

In (15a), for instance, the head $\mathrm{N}$ is al-mutqin-aa is dual and al-is also prefixed to it, the same thing can be said regarding the plural form in (15b), where al- is attached to the plural mutqinuи.

In addition, there are also data from Arabic as in $(16 \mathrm{a} / \mathrm{c})$ which show that the definite head $\mathrm{N}$ can occur in multiple CSs of different categories. For instance, in (16a) the second genitive complement $l i$-wajh-i is a PP, in (16b), a DP and in (16c) a CP (cf. Al-Sywti HHGG, II: 348350; Al-Aboudi 1985).
a. al-muSti-u
1-maal-i
li-wajh-i
illaah-i
the-giver-NOM
the-money-GEN for-face-GEN
Allah-GEN
'The giver of the money for the sake of Allah'
b. al-faqiir-aa-ni $\quad r-r a \theta-i \quad \theta-\theta y a a b-i$
the-poor-NOM.DL the-dirty-GEN the-cloth-GEN
'The two poor with the dirty cloth'
c. yuhtaram-u 1-muSllim-uu n-naas-i kaifa
is-respected-NOM the-teacher-NOM.l the-people-GEN how
'Those who teach people how to behave are respected.'

yatașarraf-uuna

behave-PL 
Note that all the embedded head Ns and GDCs are definite. However, there is also data as in

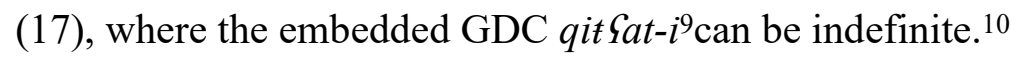

17) s-saariq-u qitYat-i n-nuquud-i

the-robber-NOM piece-GEN the-money-GEN

'The robber of a piece of the money'

Another type of support that the head N and its GDC can take the definite article comes from CSs like (18), where the head $\mathrm{N}$ al-Saalim- $u$ has the definite article al-, and its GDC has the definite article as well.
18) al-Saalim-u

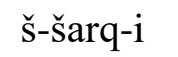
Pawşat-i
the-scientist-NOM the-east-GEN middle.GEN

'The scientist of the Middle East'

Another piece of evidence comes from ACSs as in (19), where the ACS l-jamiilat-u l-wajh-i ('the beautiful the face') allows al-. However, there are also some ACSs which do not allow al- as in (19a), which again casts some doubts on the validity of the notion bareness simply because we cannot, again, stipulate that there is bareness in adjectives.
19)
a. al-mara?at-u
1-jamiilat-u
1-wajh-i
the-woman-NOM
the-beautiful-NOM
the-face-GEN
'The woman with the beautiful face'
(*1-)laðiið-a
t-łąaam-i
ate-I
delicious-ACC
'I ate the delicious food.'
b. Pakl-tu
the-food-GEN

In (19a) the adjective $l$-jamiilat- $u$ functions as the head of the ACS whose GDC is $l$-wajh-i. In (19b), the adjective laðiið- $a$ ('delicious') functions as the head of the ACS and $t$-taSaam- $i$ functions as the GDC. In short, $(19 \mathrm{a} / \mathrm{b})$ lend us strong support to postulate that the head of a $\mathrm{CS}$, be it adjectival or nominal, is a full DP and not null as was assumed in the previous analyses. ${ }^{11}$

\footnotetext{
${ }^{9}$ In multiple CSs, a DP can function as a GDC to the preceding head N and a head to the following GDC as in the case of qit Yat- $i$ which functions as a GDC to $s$-saariq- $u$ and a head to $n$-nuquиd-i.

10 Traditional Arabic grammarians argue for the possibility of al- to be attached to the head $\mathrm{N}$ in CSs. For instance, Ibn Malik (III: 73-74) mentions five contexts, where $a$ l- can be attached to the CS. However, it should be

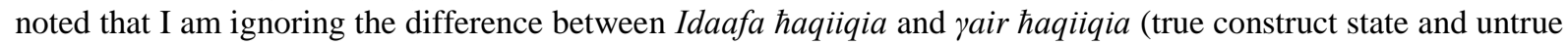
construct state, for more on this see Al-Sywti HHGG, II; Ibn Jinni; Wright 1989; Al-Aboudi 1985; among others).

11 There are two types of ACSs: i) those whose head Ns can be definite or indefinite, (i. e. with or without $a l$-) as in (19a) and ii) those whose head Ns can only be indefinite as in (19b), and this is also other evidence of what I am assuming here. In addition, there is also a well-documented phenomenon in Standard Arabic, where the negative particle laa (not) intervenes between the $a l$ - and the head $\mathrm{N}$ as in (i).

al-laa-Pinsaanya

the-not-humanity

'The inhumanity'
} 


\subsubsection{Vowel Contextualization Rule and "Invisible - $n$ "}

Perhaps, the most substantial evidence that the head $\mathrm{N}$ is indefinite comes from examples like (20), where the Dem haaðaa (this) co-occurs with a CS as a premodifier. $^{12}$

20) *haaðaa bayt-u r-rajul-i

this house-NOM the-man-GEN

Intended meaning: 'This house of the man'

(20) is ungrammatical if it has a nominal interpretation, i. e. if we consider it a DP, as is clear from the intended meaning in the English translation. It is a fact of Arabic that when Dems like haaðaa (this) function as (pre)modifiers, the modified DP must be definite. This actually accounts for the ungrammaticality of (20). However, in the clausal level, it is grammatical, i. e. if the DP is used as a predicate, the construction is grammatical as in (21).

21) haaðaa bayt-u r-rajul-i

this house-NOM the-man-GEN

'This is a house of the man.'

CSs like in (21) fail to occur in contexts preserved for definites, which simply means that the head Ns of this type of CSs are actually indefinite.

Consider (22) from Hebrew, where indefiniteness is specified. Siloni (2003: 507), following Danon (2001) and Engelhardt (2000), points out that the head N and its GDC do not have to agree in definiteness which is clear in (i) and (ii), representing indefiniteness and definiteness interpretation, respectively.

22) boger ha-universita nasa ne'um

i. 'A graduate of the university held a speech.'

ii. 'The graduate of the University held a speech.'

If our argument so far is true, i. e. the head $\mathrm{N}$ of a CS can take the definite article al-, how is it that $(23 \mathrm{~b} / 24 \mathrm{c})$ are ungrammatical? The ungrammaticality of (23b) and (24c) lies in that the head $\mathrm{N}$ co-occurs with the indefinite marker $\boldsymbol{- n}$ in the former and the definite $a l$ - in the latter. However, (23a/24b) are grammatical, because the head $\mathrm{N}$ co-occurs with neither. The ungrammaticality of $(24 \mathrm{c})$ can be ascribed to the fact that the head $\mathrm{N}$ co-occurs with both.

\footnotetext{
12 It has also been argued that certain types of deverbal CSs show no definiteness spread as shown in (i) (see also Fassi Fehri 1999: 146).

(i) a. kitaabat-u l-xabar-i sariis-an xała?-un writing-NOM the-news-GEN fast-ACC mistake-NOM 'Writing the news fast is a mistake.'
b. *kitaabat- 1-xabar-i 1-mutasrri@at-u xata?-un writing-NOM the-news-GEN the-hasty mistake-NOM

'*Writing the news the hasty is a mistake.'

In (i), the head N kitaabat- $u$ ('writing') cannot be modified by an AP modifier. Thus, modifying it with the AP $l$ mutasrriSat- $u$ ('the hasty') renders the CS ungrammatical. However, when the head $\mathrm{N}$ kitaabat- $u$ ('writing') is modified by an adverb sarii -an ('fast') as in (ia), it is grammatical.
} 
23) a. bayt-u r-rajul-i

door-NOM the-man-GEN

'The man's house'

b. *bayt-un r-rajul-i

door-NOM the-man-GEN

24)
a. *al-bayt-u
rajul-in
the-door-NOM
man-GEN
b. bayt-u
rajul-in
door-NOM
man-GEN
c. *al-bayt-u-n
r-rajul-i
the-door-NOM-INDEF
the-man-GEN

However, examples like (23b) cast doubts on the validity of our argument above. In other words, if the head $\mathrm{N}$, as stated above, can be indefinite, then why is it impossible to take the indefinite article $\boldsymbol{- n}$ ? To put it the other way around, why doesn't $\boldsymbol{n} \boldsymbol{n}$ occur on the head $\mathrm{N}$ of an indefinite CS? Answering such a question requires us to walk through the following discussion.

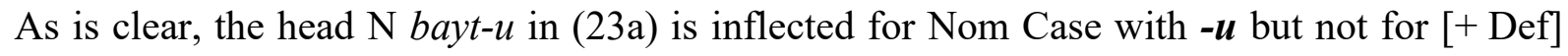
nor [-Def] feature. Given our assumption that the definite article $a l$ - and the indefinite $-\boldsymbol{n}$ are in complementary distribution (this in turn puts us vis-à-vis a difficult problem, i. e. if the definite article al- cannot co-occur with the head N) why, then, the indefinite marker cannot occur (surface) on the head N, as it is the case in other (nonconstruct) DPs. If we assume, following some linguists (see Fassi Fehri 1999; Kremers 2003; among others), that the absence of the $-n$ on the head Ns of definite nonconstruct DPs were due to the presence of the definite article $a l-$, the $-n$ would have surfaced on the head Ns of indefinite CSs like (24b). However, the reality is the otherwise, i. e. even in indefinite CSs, the $-n$ does not appear on the head $\mathrm{N}$.

In some of the previous studies, the solution provided for this problem, as argued above, was that the head $\mathrm{N}$ is bare and depends for its (in)definiteness on its GDC via (in)definiteness spread. However, it seems that this is not the case. Let us first take the English DP (though not Semitic) in (25) as an example to see how and why the indefinite article $a$ cannot co-occur with the plural noun teachers. ${ }^{13}$

25) a. *a teachers

a teacher

\footnotetext{
13 Again, if we take the notion bareness to mean that a noun appears without either article, it seems that the issue is true cross-linguistically (setting aside articleless languages). A very evidenced piece of support for our argument comes from other languages like English, for instance, a noun can be either definite or indefinite and no possibility of a third state. Let's take the English example in (i):

(i) * saw cat in the garden.

The reason of the ungrammaticality of (i) is that the noun cat occurs as a bare noun. In the same line, it is implausible to postulate that the head Ns in CSs are bare for the fact that there is no case of bare NPs attested in Arabic, so long as bareness is related to the co-occurrence of a noun with articles (see also Fassi Fehri 2004).
} 
If we ask a commonplace English person why (25a) is ungrammatical, he/she would say because the word/noun teachers never takes an indefinite article, simply because it is plural. However, to a linguist, the matter significantly differs. A linguist would rather say that the plural morpheme $-s$ bans the indefinite article $a$ to co-occur with the indefinite head teachers. Formally, there seems to be a morphological/phonological element that bans the indefinite article $a$ to co-occur with the noun teachers, which is the plural morpheme $-s$.

Now, taking our assumption that the head $\mathrm{N}$ can be definite as in (16), and that it can be indefinite as in (23a), I assume here that the inability for $-n$ to surface on the head $\mathrm{N}$ has mainly to do with phonology/morphology considerations. This assumption is supported by several phonological contexts where not only the $-n$ but also Case markers like $-u,-a$ and $-i$ do not surface on certain classes of Arabic nouns in final positions. A strong piece of evidence supporting our argument comes from such structures as (26).

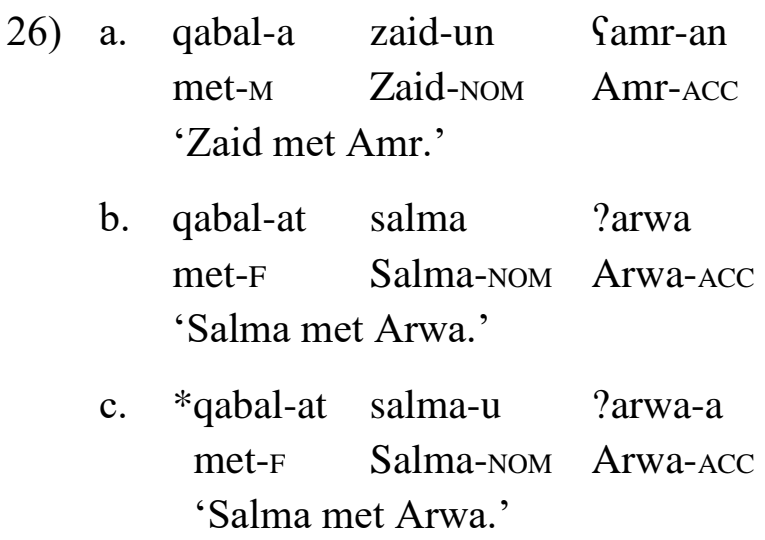

In (26a), the Nom and Acc Case markers -un and -an, respectively, occur on the nouns zaid (Zaid) and Samr (Amr), respectively. However, (26b) is grammatical while (26c) is not. What makes (26c) ungrammatical is the fact that $-u$ and $-a$ are suffixed to salma (Salma) and ?arwa (Arwa), respectively. The phonological phenomenon banning the Case markers $-u$ and $-a$ (in addition to $-n$ ) to appear on the nouns salma (Salma) and ?arwa (Arwa) ${ }^{14}$ is that both of them end in the vowel $/ a /$.

The facts manifested by (23) lead some traditional grammarians to propose that the inability of $-n$ to appear on indefinite head Ns has nothing to do with the GDC being definite or indefinite. Rather, it is only because of the GDC itself, arguing that GDC replaces the nunation $-n,{ }^{15,16}$ which seems to be related to the phonological boundary of the CSs in Ouhalla's (2009) sense. Based on this, I propose that the inability of $-n$ to occur on the head $\mathrm{N}$ is related to a context-based phonological restriction. This kind of context-based phonological restriction could be called the Vowel Contextualization Rule (VCR), the evidence of which is much attested in the language. VCR is outlined in (27).

\footnotetext{
14 The nouns Salma and Arwa are proper nouns, i. e. names of girls in Arabic.

15 See, for instance, Ibn Jinni (322-392, in his book al-xasaa?is 'The Properties'). For modern Arab linguists who support this assumption, see (Alshara'i 2014; Al-Anbārī 1997; Al-Aboudi 1985).

16 Nunation (tanwiin) in Arabic is a process whereby -un, -an or -in is added to the end of a word (noun or adjective) to indicate its declination and syntactic indefiniteness.
} 
27) VCR A word is abstractly nunated and Case marked if it ends in a vowel.

Where the word is a content word, namely noun, adjective and/or verb, and the vowel is $/ a /$ (in addition to $/ i /$ and $/ u /$, in some contexts). ${ }^{17}$

VCR can also be generalized to include two other morphemes, namely - ni and -na (dual and plural markers, respectively) attached to the head $\mathrm{N}$ in CSs which are deleted in final positions as illustrated in $(28 \mathrm{~b} / \mathrm{c})$.

28) a. kaatib-aa-ni

writer-NON-DL

'Two writers'

b. kaatib-aa l-qişşat-i

writer-NOM.DL the-story-GEN

'Two writers of the story'

c. *kaatib-aa-ni 1-qişşat-i

writer-NOM-DL the-story-GEN

'Two writers of the story'

d. *kaatib-uu-na l-qişşat-i

the-writers-NOM-PL the-story-GEN

'The writers of the story'

e. kaatib-uu 1-qişşat-i

the-writers-NOM.PL the-story-GEN

'The writers of the story'

${ }^{17}$ For a Case marker and nunation to occur on a word ending in a vowel is not possible in some cases like the vowel /a/. However, some final vowels allow some Case markers to appear on them as in the Case of $-u$ which allows the Acc - $a$ marker but not the Nom $-u$ as in (i) and (ii), respectively:

(i) Pan yasmu-a

to be-supreme

(ii) Saliyy-un yasmu- $(* u)$

Ali-NOM gets-supreme

In (i), the verb yasmu ends in $-u$ which allows the Acc marker $-a$ to occur. The vowel $/ \mathrm{i} / \mathrm{in}$ final positions allows Acc marker but not Nom as in (iii) and (iv), respectively.
(iii) Pan ya?ti-a
to come
(iv) Saliyy-un ya?ti-(*u)
Ali-NOM comes 
Some linguists (see e. g. Kremers 2003; Almansour 2012) argue that $\mathbf{- n \boldsymbol { i }}$ and $\mathbf{- n a}$ are identical to the indefinite marker $\boldsymbol{- n} .{ }^{18}$ However, it seems that this is not the case. The former never occur without the vowels $\boldsymbol{i}$ and $\boldsymbol{a}$ while the latter never co-occurs with either. The mere similarity between both morphemes is that both delete in CSs as is clear in (28a-e). However, there is still a very substantial difference between both types, i. e. while the former co-occur with $a l$-, the latter never does. This is clear in $(29 \mathrm{a} / \mathrm{b})$, where both can co-occur with al- while the indefinite marker $-n$ cannot, as illustrated in $(29 \mathrm{c} / \mathrm{e})$.

29) a. al-kaatib-uu-na

the-writers-NOM-PL

'The writers'

b. al-kaatib-aa-ni

the-writer-NOM-PL

'The two writers'

c. qalam-u-n

pen-NOM-INDEF

'A pen'

d. al-qalam-u

he-pen-NOM

'The pen'

e. *al-qalam-u-n

The-pen-NOM-INDEF

Examples in (29a-e) lend us strong support that both types of morphemes are never identical. Another piece of evidence that they are not identical comes from the fact that while $-n$ occurs only on nouns, $-n i$ and $-n a$ occur on nouns and verbs. ${ }^{19}$

VCR seems also to be available in verbs. This is supported by the inability of the morpheme $a$ to surface on Arabic verbs as illustrated in (30).

\footnotetext{
${ }^{18}$ The idea of reducing the $-n i$ and $-n a$ to just $-n$ seems to be erroneous. In fact, these two morphemes are always spelled as $-n$ and $-n i$ and $-n a$. Therefore, it is not reasonable to say that they have the same nature and distribution. There might be some kind of historical relation between both types, but this does not mean that they are identical. The difference between $-n$ and $-n i$ and $-n a$ lies in the fact that while the latter take the form $-n \mathrm{~V}$, the former $-n$ per se, and hence they are not identical. It is not clear to me what their nature is, however. In Arabic DP-split literature, they were not considered markers of any feature. Number, Person and Gender have their markers. However, I consider the $-n \mathrm{~V}$ to be dual and sound plural markers of the Poss feature (cf. Kremers 2003: 49) though the latter is so rare in Arabic. I will not discuss them any further here and I refer the interested reader to (Kremers 2003; Alsharaa'i 2014; Al-Anbārī 1997; among other related work).

${ }^{19}$ Examples of the occurrence of $-n i$ and $-n a$ are presented in (i) and (ii), respectively.

(i) yaktub-aani write.3DL

'They (DL) write'

(ii) yaktub-uuna write.3PL

'They write'
} 


$\begin{array}{lll}\text { 30) a. } & \text { ðahaba } & \text { 1-walad-u } \\ & \text { went } & \text { the-boy-NOM } \\ & \text { 'The boy went fast.' } \\ \text { b. } & \text { ðahab-(*a)-tu } & \text { musriৎ-an } \\ & \text { went-I } & \text { fast-ACC } \\ & \text { 'I went fast.' } & \end{array}$

In (30a), the verb ðahab ('went') is inflected for past tense with $\boldsymbol{- a}$ when the subject is the 3 person singular. However, when the subject is the 1 person pronoun clitic $-\boldsymbol{t} \boldsymbol{u}$, the $\boldsymbol{- a}$ is dropped (due presumably to contextualization). This, in fact, though not happening in a CS, nor does it take place in the nominal domain, but rather in the verbal domain, lends strong support to our argument that the inability of a morpheme to surface on a lexical item in general and the inability of $-n$ to surface on the head $\mathrm{N}$ of the CS in particular has only to do with phonology.

If this analysis is on the right track, we can conclude postulating that the head $\mathrm{N}$ in Semitic CSs like (23a) are indefinite DPs. But due to VCR, the $\boldsymbol{- n}$ deletes and if this is true, it follows that the operation Select selects the head N from the lexicon specified for [ \pm Def] as a UG rule, and is merged on syntax as such. This is actually in contrast with the assumption that (in)definiteness spread is related to some marked, construction-specific mechanism of Spechead agreement in [ \pm Def] features between the D of the head N and its GDC (Danon 2008). Based on this, I propose that the indefinite article $-n$ is an existing element but due to VCR, it just cannot surface, i. e. it is simply invisible. That is to say, it is only the context (annexation) that prevents the $-n$ to appear on the head $\mathrm{N}$, and the same thing can be noticed regarding $-n a$ and $-n i$. This also coincides with some proposals in the literature that the GDC substitutes "nunation" but not removes it from the syntax or even from semantics (see also Alanbari 1997; Alshara'i 2014; Al-Aboudi 1985).

\subsection{Hebrew CSs}

The wide spread belief of Hebrew CSs (the head $\mathrm{N}$ is known as nismax and the GDC as somex) is that they share almost all the properties of Arabic ones (see e. g. Danon 2001, et seq; Siloni 1991, 1997; Fassi Fehri 1993, 1999). However, there are two important issues to be addressed, which are related to CSs, and in which Hebrew differs from Arabic. First, Case, be it Nom, Acc or Gen, is abstractly marked. Second, Hebrew does not have indefinite articles; it does have a definite article, namely $h a-$, however. The existence of a definite article entails the presence of [+ Def] feature. This gives rise to the question: does the absence of the indefinite article(s) in Hebrew entail the absence of [- Def] feature? Or otherwise, does it mean that Hebrew indefinite nouns are bare? In this section, I briefly show that even though Hebrew lacks indefinite article, indefiniteness (or[- Def]) feature is present. In particular, I argue that Hebrew nominal CSs are full DPs.

The first piece of evidence that indefiniteness exists in Hebrew DPs in general and in CSs in particular comes from examples like (31), where indefiniteness is implied in Hebrew nominals via the use of the Card number equivalent to one (see e. g. Givon 1981, see also Alexiadou et al. 2007; Kremers 2003; Geist 2013). 
31) sefer exxad/ha-sefer

book (one) the-book

'a book/the book'

Based on examples like (31), Givon (1981) argues that due to the presence of exxad ('one') indefiniteness does exist in Hebrew. Exxad here is equivalent, say, to the English $a$. As observed by Givon (1981), there is controversy that Hebrew has indefinite articles. Givon argues and provides supported pieces of evidence that indefinite articles do exist in Hebrew and questions the use of exxad, axxat and xadim ('one'.M, 'one'.F and 'these', respectively) concluding, however, that they are optional to be used.

The assumption that cardinals indicate indefiniteness has been proved true crosslinguistically. That is to say, noun phrases in several languages which lack either article or both like Russian, Ukrainian, Belorussian, Serbian, Hindi, etc. are said to be full DPs (see e. g. Pereltsvaig 2007). Consider the Hindi example in (32) from (Shormani 2013: 175).

\section{2) Ravi ēka sēba khāyā \\ Ravi one apple eat.pt \\ 'Ravi ate an apple.'}

In (32), the cardinal number $\bar{e} k a$ ('one') is a determiner and functions as an indefinite article. $^{20}$

Another piece of evidence of the existence of indefiniteness in articleless languages comes from Russian. This is illustrated in (33, slightly modified from Pereltsvaig 2007: 61), where the indefiniteness/unspecificity of the head of the possessive construction čelovék ('man') prevails. $^{21}$

33) tonkogo uma čelovék
delicate mind man

'A man of delicate mind'

\footnotetext{
${ }^{20}$ Describing Hindi, Mahajan (2003: 226) maintains that "SOV languages lack a definite determiner. The role of an indefinite determiner is often played by the numeral one and many other determiner-like elements look like adjectives". In some languages, English, for instance, Lyons (1999: 8) argues that definite articles develop out of demonstrative determiners. However, indefinite articles, Lyons argues, often evolve from the Card one. For instance, Irish, which is similar to Hebrew, has only a definite article as in (i). Other languages like Turkish only mark indefinites as in (ii) from Lyons (1999: 52).

(i) Irish

a. an bord 'the table'

b. bord 'a table'

(ii) Turkish

a. ev 'house', 'the house'

b. bir ev 'a house'

${ }^{21} \mathrm{DP}$ phrase is meant to stand for a determiner phrase and not article phrase. Consequently, the existence of DP is not tied to whether a language is articled or articleless. When Abney (1987) proposes and advocates the DPHypothesis, his prior concern is how to describe the internal structure of nominals, of course, having in mind article existence. In this regard, Pereltsvaig (2007) argues that it is not easy to determine what counts as an article.
} 
Pereltsvaig (2007) maintains that, though articleless, Russian noun phrases are best analyzed under DP-Hypothesis. To her, even Parameterized-DP Hypothesis is not adequate to account for Russian noun phrases. She maintains that "the Universal-DP Hypothesis makes better predictions for Russian than its alternative, the Parameterized-DP Hypothesis". Another piece of evidence comes from grammatical structures in CSs with cardinal plurals or singulars functioning as heads, where exxad ('one') or 'xadim ('some') occurs with indefinite CSs which signal indefiniteness. This is illustrated in (34).

34) kalbei rxob xadim

dogs-C street ones

'Some street dogs'

Indefiniteness is also manifested in examples like (36) from (Heller 2002: 132).

35) a. anfey oren exad

branches pine one

'A pine's branches'

b. anfey oren

pine branches

'Branches of pine'

In (35a), there is some kind of specificity when adding the cardinal exad ('one'). That is to say, (35a) indicates some kind of specificity in pinpointing "the branches of a specific pine tree" whereas this kind of specificity is absent in (35b) (Heller 2002: 132).

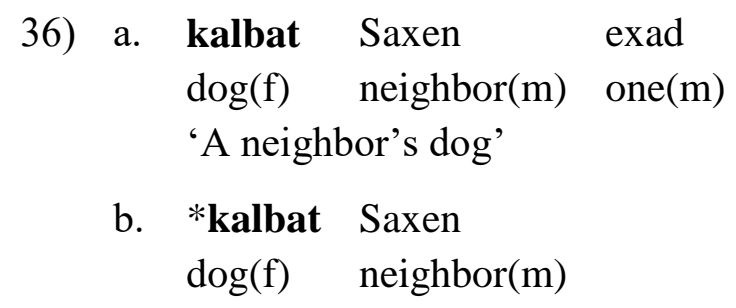

In (36a), there is an actual dog, which is not the case in (36b). Here, Heller ascribes the ungrammaticality of (36b) to the fact that it does not signal a "sub-kind of dogs such that they are owned by neighbors". She argues that the use of the numerical 'one' is meant for getting "the appropriate individual denotation" (Heller 2002: 132).

A CS being either definite or indefinite is what actually concerns us here for what has been put forth so far. I assume that indefiniteness does not exist for the fact that if it does, how is it that one feature exists (i. e. [+ Def]) while its parallel (i. e. [- Def]) does not? This is supported by the widely held assumption that a language is either articled or articleless and not both. In addition, if indefinite nouns exist in Hebrew, it seems difficult to account structurally for the morpho-syntactic forms of a complement determined by the head as in the case of Arabic kull (Hebrew $k o l$ ). When it means every, it selects indefinite count nouns. However, if it means all, it selects definite plural countable nouns or mass ones (see also Fassi Fehri 2004; Wintner 2000). What I am trying to prove is that like Arabic, Hebrew CSs without ha- are fully indefinite. 
Consider the Hebrew examples presented in (37/38, from Wintner 2000: 324) which add extra evidence that the head Ns of the CSs are not bare nouns. The occurrence of exxad ('one') and its being optional is clear.

$\begin{array}{llll}\text { 37) } & \begin{array}{l}\text { sepr ('exxad) } \\ \text { book (one) }\end{array} & \text { /ha-sepr } & \\ \text { 'A book/the book' } & \text { /the-book } & \\ \text { 38) } & \begin{array}{l}\text { sepr gadol ('exxad) } \\ \text { book big (one) }\end{array} & \text { /ha-sepr } & \text { /the-book } \\ \text { 'A big book/the big book' } & \begin{array}{l}\text { ha-gadol } \\ \text { the-big }\end{array}\end{array}$

As far as the definite article $h a$ - is concerned, Siloni (1991) assumes that the inability of the definite article to surface on CS head Ns is because of some constraint. She argues that the definite article $h a$ - cannot be prefixed to such head Ns, because those Ns are positioned in D (see also Abney 1987). In addition, Danon (2001, 2002a) describes the definiteness spread in CSs as involving no spreading of semantic definiteness. To him, only the presence of et before CSs bans an indefinite reading which could have been possible otherwise. This is illustrated in (39) from (Danon 2002a: 2).

39) Dan kara et axad ha-sfarim

Dan read et one the books

'Dan read one of the books.'

(39) is a partitive CS where exad ('one') is used to denote such partitiveness. Danon (2001) holds that there is one feature of definiteness which spreads from the GDC, viz. only formal (i. e. syntactic), and this spread is only because of the presence of et and semantic definiteness is not necessarily spread consequently. He concludes that though following et, such a partitive CSs have an indefinite interpretation. Based on (39) above, Danon (2002a: 3) maintains that a CS is (40):

40) formally definite if its embedded DP (the associate, somex) is formally definite.

He, in fact, contrasts (39) above with (41) below, where the former is syntactically definite while the latter is only semantically definite. He maintains that though the CS in (39) is semantically definite (due to the presence of the Dem ze ('this'), it has an indefinite interpretation (see also Fassi Fehri 1999: 126-128, for Arabic).

41) Dan kara sefer ze

Dan read book this

'Dan read this book.'

Based on (39, 40 and 41) above, Danon proposes (42) as a rule describing the distribution of et:

42) et precedes an object if the object is formally definite ([+ Def $])$.

Danon has also placed huge emphasis on the context (discourse) more than syntax to interpret a CS as either definite or indefinite. In (43), which is a formally definite CS, the subject tošav ha-štaxim ('resident of the-territories') has an indefinite interpretation because of "the lack of a previous context" (2002a: 3). 
43) tošav ha-štaxim ne'ecar latoxakira.

resident the-territories arrested interrogation

'A/the resident of the territories was arrested for interrogation.'

Further, in (44), the subject is a formally definite CS, which can easily be interpreted as an indefinite in the lack of a previous context.

44) bxirat hatheva'ada be-ezrax medinat yisra'el asura.

Choice committee in citizen state Israel forbidden

'Choice of an Israeli citizen by the committee is forbidden.' 22

Though the CS ezrax medinat yisra'el ('a citizen of an Israeli state') $)^{23}$ has [+ Def] feature, it has an indefinite interpretation only because it follows a preposition. He also argues that CSs like (45) do not involve definiteness spread, where the CS boger ha-xug ('graduate department') is a membership construct (i. e. its head is a membership noun) and functions as a predicate having an indefinite interpretation.

45) Dan boger ha-xug le-safrut.

Dan graduate department to-literature

'Dan is a graduate of the literature department.'

Like in Arabic (see e. g. Fassi Fehri 1999), Engelhardt (2000) notes that there is another class of CSs in Hebrew, where definiteness spread does not take place (see also Kremers 2003). This class is called deverbal CSs like (46).

46) ktivat ha-sefer

writing the-book

'The writing of the book'

Some linguists argue that definiteness spread is just a matter of interpretation, postulating that it is only et which bans a definite CS from having an indefinite reading (Ritter 1991; Siloni 1997; Engelhardt 2000; Danon 2001, 2002a/b; among others). Like Benmamoun (2003), Danon (2006: 998) finds it difficult to account for why number does not spread in tmunat hayeladim (Lit: 'picture the-children'). Though the GDC is plural, the head is singular. So is the whole CS. ${ }^{24}$ Engelhardt $(2000)^{25}$ and Danon $(2001,2006)$ argue that there is no indefinite spread in Hebrew CSs. They argue that the indefinite nature of CSs is due to the lack of the

22 This English gloss is as provided in (Danon 2002a: 4) where the word state is not provided.

${ }^{23} \mathrm{I}$ am not also sure of this gloss, it is based on my intuition.

24 See Siloni (2001) who develops an elaborate PF-based analysis of the CS. She maintains that attaching the definite article to the head of a CS is what renders a CS ungrammatical. However, she was, (Danon 2001) noted, unable to derive definiteness spread as a feature from the prosodic structure.

25 Engelhardt (2000: 71) argues that definiteness spread does not take place in CSs in some contexts where definites are not allowed as in (i):

$\begin{array}{llll}\text { (i) a. } & \text { ruti mevala et zmana } & \text { be-/*ba-ktiva } \\ & \text { ruti spends OM time } & \text { in-/*in.Def-writing } \\ & \text { 'Ruti spends her time writing.' } & \\ \text { b. } & \text { rut mevala et be-ktivat ha-sefer } \\ & \text { Ruti spends OM time.3F.SG in-writing the-book } \\ & \text { 'Ruti spends her time writing the book.' }\end{array}$

Engelhardt argues that the sentence in (ia) the complement of the preposition $b e$ - 'in' in such sentences must be indefinite: the PP where ba-ktiva ('in the writing') is definite renders the sentence ungrammatical. The same thing can be said about the CS ktivat ha-sefer in (ib). 
definite article that cannot be prefixed to the head N. ${ }^{26}$ In addition, Shlonsky (2004) maintains that the absence of indefinite article in Hebrew is just a phonetic phenomenon rather than a syntactic or semantic one. There is still another type of CS in which (in)definiteness spread does not take place, viz. deverbals (see e. g. Engelhardt 2000) and from a structural point of view, Dobrovie-Sorin proposes that

(in)definiteness spread is an interpretive consequence triggered by genitive specifiers, and since complements of $\mathrm{N}^{\circ}$ impose no constraint on Det's, the existence of indefinite CSN's [nominal construct states] with definite complements of $\mathrm{N}$ is not surprising.

(2001: 75)

She concludes that Hebrew CSs are of three possible configurations, only one of which has the associate in Spec-N which is alone comparable to Romanian genitives and English Saxon ones. In addition, Alexiadou (2003) maintains that definiteness spread is not a universal. In other words, there are languafges like Greek, where definiteness spread is not obligatory. Alexiadou (2006) adds that definiteness spread of the Scandinavian type is not an obligatory process in all varieties.

Furthermore, context has also been taken into consideration in this regard. Context can also provide indefiniteness readings even if the definite article $h a$ - is present. The use of the Dems and the numeral one giving rise to article possibility has been noticed in some languages, the Romance languages, for instance. Some syntacticians tend to believe that some processes like the use of Dems and the numeral one seem to be language universal, and hence the tendency that even articleless languages may lead to establishing articles (Danon 2001). Borer (1996) argues against N-to-D movement, maintaining that there is data supporting the surface word order in CSs. Based on this assumption, Danon (2001) argues that definiteness spread is just a matter of some kind of phonological weakness unique to CSs, which supports our proposal of VCR. It is not also possible to think of having a language with only one type of article but not with another, and it is also clear from our discussion that it is difficult to determine "what counts as an article" (Pereltsvaig 2007: 59).

Shlonsky (2004) and Danon (2002) assume that the article ha- of the head N of Hebrew CSs is syntactically and semantically present, and that there is something banning it from being attached to the head $\mathrm{N}$. This actually follows from the fact that if we assume for the moment that there is definiteness spread in Hebrew, which means that the head becomes definite, which also means that the [+ Def] feature is present on the head $\mathrm{N}$, the question is how can we account for this feature and how it can be checked/valued, let alone other features? An answer to this question is provided by Danon (2002b) who proposes a "DP-ness Spreading" rather than definiteness spread. Danon explains his proposal from a structural point of view. He assumes that, because definiteness requires structural Case, CSs with a definite GDC require a complex structure in which Case assignment is possible.

The assumption that the head $\mathrm{N}$ can occur with $h a$ - in Hebrew CSs has been considered, but it is not very much clear and is almost controversial (Elizabeth Ritter, pers. comm.). Some Hebrew scholars (e. g. Borer 1999; Siloni 1997) assume that there is an abstract definiteness morpheme. This morpheme is base-generated on the head N. This assumption actually makes

\footnotetext{
${ }^{26}$ Dobrovie-Sorin (2001: 76) uses the term "determiner" to refer to Dems, cardinals, articles, etc. though Danon (2001) considers Dems definite elements, a position held by all Arabic scholars.
} 
the possibility of having a definite article attached to the head $\mathrm{N}$ available. However, I will follow Shlonsky (2004) who assumes (contra Borer and Siloni) that the article ha- is the head of the DP and that nothing merges with it, and thus, the definite article in Semitic perhaps parallels the article in languages like English (Shlonsky 2004).

Danon (2008: 139-140), for instance, argues that in Hebrew, specifically colloquial Hebrew $(=\mathrm{CH})$, it is very common that $h a$ - can be attached to the head N in CSs (47) shows. ${ }^{27}$

47) ha-aremat dapim ha-zot

the-pile papers the-this

'This pile of papers'

In (47), the head N ha-aremat appears with the definite article ha-. In addition, Siloni (2001: 153-154) argues that in $\mathrm{CH}$, "there is an ongoing process relocating the article before the head of the construct. The process obeys yet unexplored constraints". Differently from Danon, she argues that attaching $h a$ - to the head $\mathrm{N}$ is "to be sensitive to the position of the construct in the sentence" as illustrated in (48).

48) kvar avarti [ta-bdikat rofe]

already passed (I) ACC+the+examination physician

Some other Hebrew scholars (see e. g. Sichel 2002; Shlonsky 2004) have gone even further, arguing for the independency of $h a$ - as a separate head inserted in D in Hebrew. They argue that $h a$ - is a free morpheme and not a bound one. Along these lines, Sichel (2002) argues that in Hebrew CSs $h a$ - is an independent element building her conclusion on the fact that some elements, like adjectives, can intervene between $h a$ - and another AP functioning attributively which agrees in definiteness with the head $\mathrm{N}$ it modifies. This is illustrated in (49) (from Sichel 2002: 334).

\footnotetext{
27 Some linguists (see e. g. Shlonsky 2004; Sichel 2002; Shormani 2016) go even further ascertaining that D is an independent head, supporting their arguments with crucial evidence from data where a constituent intervenes between the head N and its GDC. Consider (ia), from Arabic (cf. Shormani 2016), and (ib/c) from Hebrew (Sichel 2002: 303) (see also fn. 13 above)
(i) a. al-laa-Pinsaanyat-u (şifat-un maðmuumat-un)
the-not-humanity-NOM (quality-NOM disliked-NOM)

'The inhumanity (is a disliked quality).'
b. Ze kvar [ha-pakid ha-legamrey mebulbal ha-revi'i] Se-dibarti ito hayom this already the-clerk the-completely confused the-forth that-talked.i with-hi today

'This is already the forth completely confused clerk I've talked to today.'

$\begin{array}{lllllll}\text { c. [ha-mis'ada } & \text { ha-lo } & \text { kSera } & \text { ha-yexida } & \text { be-bnei brak] } & \text { nizgera } & \text { ha-Savu'a. } \\ \text { the-restaurant } & \text { the-neg } & \text { kosher } & \text { the-sole } & \text { in-bnei brak } & \text { closed } & \text { this-week }\end{array}$
}

In (ia), the negative particle laa- ('not') intervenes between al- and the head $\mathrm{N}$ Pinsaanyat- $u$, which is very productive in the language. In (ib/c), Sichel (2002: 303) argues that in Hebrew CSs, $h a$ - is an independent element, building her conclusion on two facts: i) an AP functioning attributively can intervene between $h a$ - and the head $\mathrm{N}$, as in (ib) and ii) a negative particle can intervene between $h a$ - and the head $\mathrm{N}$ as in (ic). 
$\begin{array}{rlll}\text { 49) a. } & \begin{array}{l}\text { ha-xulca } \\ \text { the-shirt }\end{array} & \begin{array}{l}\text { ha-yekara } \\ \text { the-expensive }\end{array} & \begin{array}{l}\text { beyoter } \\ \text { most }\end{array} \\ \text { b. *ha-xulca } & \begin{array}{l}\text { ha-beyoter } \\ \text { the-shirt }\end{array} & \begin{array}{l}\text { yekara } \\ \text { the-most }\end{array}\end{array}$

In (49), the adjective yekara ('expensive') intervenes between the -ha and the AP beyoter ('most'). If this is not the case, the structure is rendered ungrammatical as (49b) shows.

To conclude this section, I will assume, following these authors, that in Hebrew CSs the head Ns are definite and indefinite. I also assume, following them, that the article $h a$ - can be attached to the head $\mathrm{N}$ in Hebrew CSs.

\section{Definiteness vs. Uniqueness}

There is much research in the literature on the relation between definiteness and uniqueness particularly in the semantic studies of definiteness (see Woidich/Heinen-Nasr 2005; Wright 1898; Brustad 2000; Givon 1979; Kamp 1981, 2011; Al-Tunji/Al-Asmar/Ya qub 1993; Janda 1999; Abney 1987; Lyons 1999; Heller 2002; Dobrovie-Sorin 2001, 2003; among other related work) which relates both notions to one another. The relation is based on where both diverge and where they converge. Let us assume that definiteness is a universal in all languages and this universal is parameterized (see also Lyons 1999; Woidich/Heinen-Nasr 2005; Kamp 1981, 2011). Lyons (1999: 278), for instance, points out that definiteness is universal being "an element of interpretation in all languages". Given the assumption that definiteness is parameterized, I assume that it is so in relation to the presence or absence of articles. Some languages have articles whereas others do not, the former is represented by languages like English, Arabic, German, etc. and the latter by languages like Turkish, Russian, Mandarin, etc. A definite article is defined by Lyons (1999: 6) as "a grammatical word with no descriptive lexical content".

Uniqueness, on the other hand, is definded by von Heusinger (2002: 268) as a discourse factor making use of "an expression [as] referentially anchored to another object in the discourse". If this is true, it seems that uniqueness is conditioned by discourse and as pointed out by von Heusinger, the discourse of uniqueness is the sentence, where a DP referentially anchored is functionally tied to a referent, i. e. another expression in the sentence or to the speaker of such a sentence. I assume, following (Heller 2002; Lyons 1999; Dobrovie-Sorin 2001, 2003; Danon 2001), that a particular CS can have the parameterized interpretation in (50).

50) CS --> Definite Unique



These CS properties are instantiated in (51-53), respectively. 

51) a. PaSti-ni 1-ka?s-a 1-fiđđat-i
give.me the-cup-ACC the-sliver-GEN
'Give me the silver cup.'
b. raPay-tu al-munfiq-a 1-maal-i
saw-I the-giver-ACC the money-GEN
'I saw the giver of the money.'

In (51a), the CS al-ka?s-a l-fidđat-i has the head N al-ka?s-a definite (by virtue of having alattached to it), and the same can be said about its GDC l-fiddat- $i$, which means that the whole CS is definite. It is also unique, because the speaker wants his/her addressee to give him/her the silver cup. In fact, (51a) is said in a situation in which there are cups made of different materials like silver, gold, glass, etc., and what the speaker wants is only the silver one. In (51b), however, the CS al-munfiq-u l-maal-i is not unique though both members are definite by virtue of having al- attached to both of them. This CS is definite but not specific/unique, because the speaker does not specify a particular person who is the giver of the money. In other words, it is implausible to think of only one person as the giver of the money in this context.

Now, consider how a CS like $(52 \mathrm{a} / \mathrm{b})$, even when the head $\mathrm{N}$ is indefinite, could be interpreted

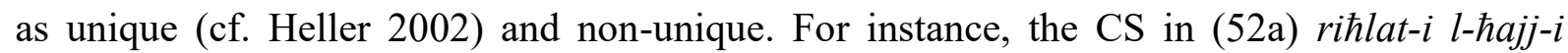
(a trip of the pilgrimage) is indefinite due to having an indefinite head, namely riћlat- $i$ and its GDC is definite.
52) a. nahnu fii riћlat-i 1-hajj-i
we in trip-GEN the pilgrimage-GEN
'We are in a trip of the pilgrimage.'
b. hal ra?ay-ta bayt-a 1-waziir-i
Q seen-you house-ACC the-minister-GEN
'Have you seen a house belonging to the minister?'

Though the head $\mathrm{N}$ of the CS is indefinite in (52a), the CS is interpreted as unique. In (52b), however, though the CS has the same structure like (52a), the CS, as a whole, is interpreted as nonspecific in (52b).

Put simply, suppose a question like (52b) is asked to one of us, such a question gives rise to/entails another question, i. e. Payy-a waziir-in ('which minister') which, in a way or another, makes it clear that there is no a specific minister being talked about. Crucial evidence that the CS bayt-a l-waziir-i ('a house belonging to the minister') is indefinite is that the question which is in the form of a CS, i. e. ?ayy-a waziir-in (which minister, where ?ayy-a is the head and waziir-in is its GDC) is indefinite. In other words, in Arabic, and specifically in such a situation, to prefix the al- to the GDC like Payy-a l-waziir-i ('which the minster') is ungrammatical. Thus, (52b) is similar to (53) where the GDC waziir-in is indefinite. 
53) hal raPay-ta bayt-a waziir-in?

Q saw-you house-ACC minister-GEN

'Have you seen a house belonging to the minister?'

Walking through (51-53), it is clear that we cannot tie definiteness to uniqueness and/or vice versa. It seems crucial that there is a substantial difference between, for instance, to say that a $\mathrm{CS}$ is (in)definite and to say it is (un)specific/(non)unique. I assume, therefore, following (Dobrovie-Sorin 2001, 2003; Heller 2002; Alshara'i 2014; among others), that (in)definiteness spread does not take place in Semitic CSs if one takes it from a formal perspective, i. e. purely syntactic.

However, there still remains one crucial point that has to be shed light on in this section. Recall that in section 1, the assumption (in)definiteness spread was based on is the agreement (concord) between the head $\mathrm{N}$ and the AP modifier modifying it in (in)definiteness. Consider $(54 \mathrm{a} / \mathrm{b})$, similar constructions to $(1 \mathrm{a} / \mathrm{b})$.

54)
book-NOM the-student-GEN the-big-NOM
'A big book belonging to the student'
a. kitaab-u $\mathrm{t}$-taalib-i l-kabiir-u
b. kitaab-u taalib-in kabiir-un
book-NOM student-GEN big-NOM
'A big book belonging to a student'

In $(54 \mathrm{a} / \mathrm{b})$, the agreement is between the AP modifier (l-)kabiir- $u$ and the head $\mathrm{N}$ kitaab-u, definite in (54a) and indefinite in (54b). However, this is untenable for several reasons: i) irrespective of Case, and taking only (in)definiteness agreement between the head $\mathrm{N}$ and the AP modifier, it is more tenable to argue that the latter follows the GDC in its (in)definiteness rather than the head $\mathrm{N}$, ii) why is it that the head $\mathrm{N}$ agrees with its GDC only in (in)definiteness and not in any other feature like Case and/or $\phi$-features?, iii) why is it necessary to base our conclusions on only one type of modifiers while there are other modifiers like PP and CP as in (55a) and (55b), respectively, where agreement is not necessary (modified from Shormani 2014a: 9/30; see also Shormani 2014b)?

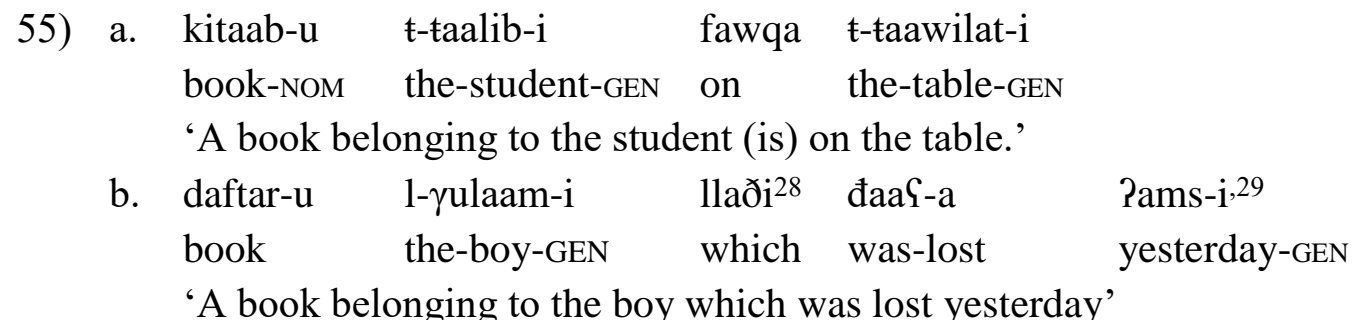

\footnotetext{
${ }^{28}$ Note that the $l$-attached to the relative pronoun $l l a ð i$ is part of it and not the definite article $a l$-.

${ }^{29}$ Another interpretation the CS in (55b) has is given in (i):

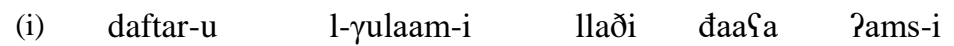 book-NOM the-boy-GEN who was.lost yesterday-GEN

'The boy's book which/who was lost yesterday...'

Unlike (55b), however, it is the genitive DP complement, viz. $l$-rulaam-i ('the boy') in (i) which is modified by the CP llaði đaaSa Pams-i ('who was lost yesterday'). Shormani (2014a) considers CSs like (55b) ambiguous, i. e. having more than one interpretation.
} 
And vi) partial agreement between a head $\mathrm{N}$ and its AP modifier(s) in (in)definiteness has been attested in the language. Consider the contrast between $(56 \mathrm{a} / \mathrm{b})$.
56) a. al-mar?at-u
1-jamiilat-u
1-wajh-i
the-woman-NOM the-beautiful-NOM
the-face-GEN
'The woman with the beautiful face'
b. al-mara?at-u jamiilat-u 1-wajh-i
the-woman-NOM beautiful-NOM the-face-GEN
'The woman with a beautiful face'

In (56a), the head l-jamiilat- $u$ of the ACS agrees with the head N al-mara?at- $u$ ('the woman') in definiteness, i. e. both are definite. However, in (56b), it does not, i. e. while the adjective is indefinite, the head $\mathrm{N}$ is definite, but still the construct in (56b) is grammatical. The adjective jamiilat- $u$ is a head of an ACS in both ( $56 \mathrm{a} / \mathrm{b})$ whose GDC is $l$-wajh-i ('the face').

It may be said that the head $\mathrm{N}$ in (56a), namely al-mara?at- $u$ is not in a construct, i. e. it is not a head of a CS. But the fact that the same property does exist in CSs is supported by examples like (57).
57)
a. kitaab-u
t-taalib-i
1-jadiid-u
1-yilaaf-i
book-NOM the-student-GEN the-new-NOM the-cover-GEN
'A book with the new cover belonging to the student'
b. kitaab-u t-faalib-i jadiid-u 1-yilaaf-i
book-NOM the-student-GEN new-NOM the-cover-GEN
'A book with a new cover belonging to the student'

In (57), the AP modifier l-jadiid- $u$ is definite in (57a) and indefinite in (57b). As it turns out, then, the claim that the agreement between the head $\mathrm{N}$ and its AP modifier in (in)definiteness seems to be not very clear a criterion to assume that (in)definiteness spread exists. ${ }^{30}$

\footnotetext{
30 Partial agreement is in the sense that the two constituents (here the head N and its GDC) agree in a subset of $\phi$-features, Case and (in)definiteness. The head N and its GDC do not agree in gender, person or number shown in (ia-c), respectively while (d) in all altogether.
(i) a. banaat-u r-ražul-i
girls.F-NOM the-man.M-GEN
'The man's daughters'
b. mudarris-u 1-awlaad-i
teacher.SG-NOM the-boy.PL-GEN
'The boys' teacher'
c. kitaab-i
book-my
'My book'
d. sakan-u 1-banaat-i
hostel.M.SG-NOM the student.F.PL-GEN
'The students' hostel'

The idea that the head $\mathrm{N}$ does not have to agree with its GDC in all $\phi$-features and Case, and that it has to agree with it in definiteness seems unreliable. 
Still however, the uniqueness/specificity attributed to the head $\mathrm{N}$ by the construct state structure cannot be denied. But, then, this cannot be ascribed to the notion definiteness (let alone indefiniteness) for the fact that definiteness is a syntax-based property, while uniqueness/specificity is a semantic one. I assume, following (e. g. Danon 2001; Dobrovie-Sorin 2001, 2003; Heller 2002; Longobardi 1996, 2001), that there is no (in)definiteness spread in Semitic CSs. I propose that the uniqueness/specificity denoted by the head $\mathrm{N}$ from individual to individual in (type $<$ e, e $>$ ) is a matter of a semantic rule of UG which is specific to CSs not only in Semitic but also in languages with preposition-less genitives like Romanian. To adopt Borer's (1999) notion of percolation, I assume that this percolation belongs to semantics and is determined by UG. However, this percolation needs to be investigated in a fully-fledged theory that would be able to account for how percolation takes place in CSs. This is due to the fact that there is no specific range of definiteness interpretations in a CS having "been fully described until now, let alone analyzed and explained from a theoretical point of view", and as such (in)definiteness spread "presents an interesting puzzle for models of syntax and the syntax-semantics interface" (Danon 2008: 872). In addition, the question whether there is correlation between semantics and syntax in this aspect is still unanswered up to date. For instance, Danon (2001: 1071) points out that formal definiteness, which is a syntax-based feature, "does not simply correlate with semantic definiteness".

As for the specificity/uniqueness denoted by the head $\mathrm{N}$ of a CS in some contexts, I propose that such specificity denotation has nothing to do with definiteness spread, but it could be linked to a UG principle or parameter. In case of a UG principle, I assume that specificity is a feature of possessivization cross-linguistically. For instance, in the case of English possessive (genitive) DPs such as a teacher's house and the teacher's house, though the head N house does not have either definite or indefinite article, it is interpreted as indefinite in the former, and definite in the latter. Thus, if we assume that it is possessivization that determines the cross-linguistic rules of specificity, it could be postulated that it is UG per se that gives possessivization this space, which has nothing to do with (in)definiteness spread. If, however, we assume that specificity takes place only in Semitic CSs, it could be argued that there is a UG parameter which specifies that Semitic languages choose such a parameter while other language families do not.

\section{Conclusion}

This article has developed a theory of formal (in)definiteness of the head $\mathrm{N}$ in Semitic CSs, arguing against a long established tradition that the head $\mathrm{N}$ in a CS acquires its (in)definiteness from its GDC via (in)definiteness spread. In support of my assumptions, I propose the VCR which accounts for the absence of the indefinite $-n$ in Arabic, concluding that the former refers to those CSs which are syntactically and semantically definite. Syntactically definite in the sense that the definite article al-is attached to the head N, and semantically definite means it is denoted by the semantics of the definite article. The latter, however, refers to those head Ns which are syntactically indefinite indicated by the absence of the definite article. Context has also been shown as an important ingredient in determining the semantics (i. e. interpretation) of a construct state, which makes the CS unique or specific. As for Hebrew, I have attempted to prove that what applies to Arabic applies also to Hebrew, providing ample evidence supporting my view. I have argued that though Hebrew lacks an 
indefinite article, (in)definiteness does exist, building my argument on a myriad of studies on this language (see e. g. Danon 2001, et seq; Pereltsvaig 2007; Heller 2002; Dobrovie-Sorin 2001, 2003). As for the possibility of attaching $h a$ - to the head N, I have built on some Hebrew scholars (see e. g. Shlonsky 2004; Sichel 2002, 2003; Danon 2008). Regarding the specificity or uniqueness denoted by the head $\mathrm{N}$ or by the CS as a whole, I have proposed that such specificity has nothing to do with definiteness spread, it may rather be a rule specified by UG as a principle in the case of possessivization cross-linguistically, or a parameter in the case of Semitic CSs. The assumption that $a l-/ h a$ - is an independent head, and that it is a free (but not bound) morpheme needs further investigation, and I leave this for future studies.

\section{References}

Abney, Steven (1987): The English Noun Phrase in its Sentential Aspect. Cambridge: MIT Working Papers in Linguistics.

Al-Aboudi, Fahmi (1985): The Syntax of 'Idafah'. Annexation in Arabic. Bloomington/IN: Ann Arbor.

Al-Anbārī, 'Abd-ar-Raḥmān Ibn-Muhammad (1997): KitābAsrār al-'arabīya. Dimašq: Mağma' al-Luğa al- 'Arabīya.

Alexiadou, Artemis (2001): Functional Structure in Nominals. Nominalization and Ergativity. Amsterdam/Philadelphia: Benjamins.

Alexiadou, Artemis (2003): "Adjective Syntax and (the Absence of) Noun Raising in the DP”. In: Mahajan, Anoop (ed.): Head-Movement and Syntactic Theory. Los Angeles, University of California Press: 1-39. (= UCLA Potsdam Working Papers in Linguistics 10).

Alexiadou, Artemis (2005): "A Possessive Adjective in the Greek DP". In: Stavrou, Melita/Terzi, Arhonto (eds.): Advances in Greek Generative Syntax. Amsterdam/Philadelphia, Benjamins: 127-151.

Alexiadou, Artemis (2006): The Fine Properties of (In)definiteness Spreading. Ms., University of Stuttgart, Germany.

Alexiadou, Artemis/Haegeman, Liliane/Stavrou, Melita (2007): Noun Phrase in the Generative Perspective. Berlin: de Gruyter.

Almansour, Abdulrahman (2012): "A Phase-Based Approach to the Construct State". Journal of King Saud University. Languages and Translation 24/1: 23-34.

Alshara'i, Abdullah (2014): "Morphology and Tanwiin. A New Account for the Interpretation of Tanwiin in Arabic". Al-Qalam Journal 1: 235-263.

AlSywti: (HHGG) Ham'?alHawaama' fii Sharh Gam' ?alGawaami', II. Almaktaba Ashaamila. http://shamela.ws/browse.php/book-6975/ [22.11.2016].

Al-Tunji, Muhammad/Al-Asmar, Raji/Ya`qub, Imil (1993): Al-Mu jam al-mufassal fi- 'ulum al-lughah. (al-alsuniyyat). Beirut: Dar al-Kutub al-'Ilmiyyah. (= al-Khazanah allughawiyyah).

Benmamoun, Elabbas (2000): The Feature Structure of Functional Categories. A Comparative Study of Arabic Dialects. Oxford etc.: Oxford University Press.

Benmamoun, Elabbas (2003): "Agreement Parallelism between Sentences and Noun Phrases. A Historical Sketch". Lingua 113/8: 747-764.

Borer, Hagit (1988): "On the Morphological Parallelism between Compounds and Constructs”. In: Booij, Gert/van Marle, Jaap (eds.): Yearbook of Morphology. Dordrecht, Foris: $45-65$. 
Borer, Hagit (1996): “The Construct in Review". In: Jacqueline, Lecarme/Lowenstamm, Jean/Shlonsky, Ur (eds.): Studies in Afroasiatic Grammar. The Hague, Holland Academic Graphics: 30-61.

Borer, Hagit (1999): "Deconstructing the Construct". In: Johnson, Kyle/Roberts, Ian (eds.): Beyond Principles and Parameters. Essays in Memory of Osvaldo Jaeggli. Dordrecht etc., Kluwer Academic: 43-89.

Brustad, Kristen (2000): The Syntax of Spoken Arabic. A Comparative Study of Moroccan, Egyptian, Syrian, and Kuwaiti Dialects. Georgetown: Georgetown University Press.

Castillo, Juan/Drury, John/Grohmann, Kleanthes (2000): "Merge over Move and the Extended Projection Principle". In: Struijke, Caro/Grohmann, Kleanthes (eds.): Proceedings of the Maryland Mayfest on Morphology 1999. College Park, MD, University of Maryland: 63-103. (= Working Papers in Linguistics 10).

Chomsky, Noam (2007): "Approaching UG from below". In: Sauerland, Uli/Gartner, Hansmartin (eds.): Interfaces + Recursion = Language? Chomsky's Minimalism and the View from Syntax-Semantics. Berlin/New York, de Gruyter: 1-30.

Cinque, Guglielmo (2003): "Greenberg's Universal 20 and the Semitic DP". University of Venice Working Papers in Linguistics 10/2: 45-61.

Cinque, Guglielmo (2005): "Deriving Greenberg's Universal 20 and Its Exceptions". Linguistic Inquiry 36/3: 315-332

Danon, Gabi (2001): "Syntactic Definiteness in the Grammar of Modern Hebrew". Linguistics 39/6: 1071-1116.

Danon, Gabi (2002a): “The Hebrew Object Marker and Semantic Type”. In: Falk, Yehuda (ed.): Proceedings of IATL 17. The Israel Association for Theoretical Linguistics. https://www.iatl.org.il/?page_id=155 [22.11.2016].

Danon, Gabi (2002b): Case and Formal Definiteness. The Licensing of Definite and Indefinite Noun Phrases in Hebrew. Tel Aviv University.

Danon, Gabi (2006): "Caseless Nominals and the Projection of DP". Natural Language and Linguistic Theory 24/4: 977-1008.

Danon, Gabi (2008): "Definiteness Spreading in the Hebrew Construct State". Lingua 118/7: 872-906.

Dobrovie-Sorin, Carmen (2000): “(In)definiteness Spread. From Romanian Genitives to Hebrew Construct State Nominals". In: Motapanyane, Virginia (ed.) (2001): Comparative Studies in Romanian Syntax. Amsterdam etc., Elsevier: 177-226. (= North Holland Linguistic Series 58).

Dobrovie-Sorin, Carmen (2002): "From DPs to NPs. A Bare Phrase Structure Account of Genitives”. In: Coene, Martine/d'Hulst, Yves (eds.): From NP to DP. Vol. 2: The Expression of Possession in Noun Phrases. Amsterdam/Philadelphia, Benjamins: 75-120.

Doron, Edit/Meir, Irit (2013): “Construct State. Modern Hebrew”. In: Khan, Geoffrey (ed.) (2013): The Encyclopedia of Hebrew Language and Linguistics. Leiden/Boston, Brill: 581-589.

Engelhardt, Miriam (2000): “The Projection of Argument-Taking Nominals". Natural Language and Linguistic Theory 18/1: 41-88.

Falk, Yehuda (2006): "Constituent Structure and Grammatical Functions in the Hebrew action Nominal". In: Grimshaw, Jane et al. (eds.): Architectures, Rules, and Preferences. A Festschrift for Joan Bresnan. Stanford, CSLI Publications: 185-207. 
Fassi Fehri, Abdelkader (1989): "Generalized IP Structure, Case, Inflection and VS Word Order”. In: Laka, Itziar/Mahajan Aanoop (eds.): Functional Heads and Clause Structure. Cambridge, MIT: 75-113. (= MIT Working Papers in Linguistics 10).

Fassi Fehri, Abdelkader (1993): Issues in the Structure of Arabic Clauses and Words. Dordecht: Kluwer Academic.

Fassi Fehri, Abdelkader (1999): “Arabic Modifying Adjectives and DP Structures". Studia Linguistica 53/2: 105-154.

Fassi Fehri, Abdelkader (2004): "Nominal Classes, Reference, and Functional Parameters, with Particular Reference to Arabic”. In: Pica, Pierre/Rooryck, Johan/van Craenenbroeck, Jeroen (eds.): Linguistic Variation Yearbook 4. Amsterdam/Philadelphia, Benjamins: 41108.

Fassi Fehri, Abdelkader (2009): “Arabic Silent Pronouns, Person, and Voice”. Brill's Annual of Afroasiatic Languages and Linguistics 1: 3-40.

Gebregziabher, Keffyalew/Ritter, Elizabeth (2013): Projecting Possessors. A Morphosyntactic Investigation of Nominal Possession in Tigrinya. Unpublished $\mathrm{PhD}$ dissertation, Calgary University, Alberta.

Geist, Ljudmila (2013): "Bulgarian Edin. The Rise of an Indefinite Article". In: Junghanns, Uwe et al. (eds.): Formal Description of Slavic Languages. Frankfurt/Main, Lang: 125148. (= Proceedings of FDSL 9).

Givón, Talmy (ed.) (1979): Discourse and Syntax. New York etc.: Academic Press. (= Syntax and semantics 12).

Givón, Talmy (1983): “Topic Continuity in Discourse. An Introduction”. In: Givón, Talmy (ed.): Topic Continuity in Discourse. A Quantitative Cross-Language Study. Amsterdam/Philadelphia, Benjamins: 1-41.

Heller, Daphna (2002): "Possession as a Lexical Relation. Evidence from the Hebrew Construct State". In: Mikkelsen, Line/Potts, Christopher (eds.): Proceedings of the TwentyFirst West Coast Conference on Formal Linguistics. Somerville/MA, Cascadilla Press: 127-140.

von Heusinger, Klaus (2002): "Specificity and Definiteness in Sentence and Discourse Structure". Journal of Semantics 19/3: 245-274.

Ibn Jinni [Pibn Jinni]: al-xasaa?is. Almaktaba Ashaamila. http://shamela.ws/index.php/ book/9986 [22.11.2016].

Ibn Malik [Pibn Maalik]: Pawđaћ Pamasaalik Pila Palfiat Ibn Malik. Almaktaba Ashaamila. https://archive.org/details/awda7-almassalik [22.11.2016].

Janda, Laura (1999): "Whence Virility? The Rise of a New Gender Distinction in the History of Slavic". In: Margaret, Mills (ed.): Slavic Gender Linguistics. Amsterdam/Philadelphia, Benjamins: 201-228.

Kamp, Hans (1981): “A Theory of Truth and Discourse Representation”. In: Groenendijk, Jeroen/Janssen, Theo/Stokhof, Martin (eds.): Formal Methods in the Study of Language. Amsterdam, Mathematical Centre: 277-322.

Kamp, Hans (2011): "Definiteness". In: Maienborn, Claudia/von Heusinger, Klaus/Portner, Paul (eds.): Semantics. An International Handbook of Natural Language Meaning. Berlin/New York, de Gruyter: 1024-1057.

Kremers, Joost (2003): The Arabic Noun Phrase. A Minimalist Approach. Utrecht: LOT. 
Longobardi, Giuseppe (1994): "Reference and Proper Names. A Theory of N-Movement in Syntax and Logical Form". Linguistic Inquiry 25/4: 609-665.

Longobardi, Giuseppe (1996): "On the Typological Unity of Indo-European and Semitic Genitive Case”. In: Lecarme, Jacqueline/Lowenstamm, Jean/Shlonsky, Ur (eds.): Studies in Afroasiatic Grammar. Papers from the Second Conference on Afroasiatic Languages, Sophia Antipolis 1994. The Hague, Holland Academic Graphics: 179-214.

Longobardi, Giuseppe (2001): "The Structure of DPs. Some Principles and Parameters, and Problems". In: Baltin, Mark/Collins, Chris (eds.): Handbook of Contemporary Syntactic Theory. Oxford, Blackwell: 562-603.

Lyons, Christopher (1999): Definiteness. Cambridge: Cambridge University Press.

Mahajan, Anoop (2003): "Word Order and (Remnant) VP Movement". In: Karimi, Simin (ed.): Word Order and Scrambling. Oxford, Blackwell: 217-237.

Mohammad, Mohammad (1988): "On the Parallelism between IP and DP". In: Borer, Hagit (ed.): WCCFL 7. The Proceedings of the Seventh West Coast Conference on Formal Linguistics. Stanford, CSLI: 241-254.

Mohammad, Mohammad (1999): "Checking and Licensing inside DP in Palestinian Arabic". In: Benmamoun, Elabbas (ed.): Perspectives on Arabic Linguistics XIII. Papers from the Twelfth Annual Symposium on Arabic Linguistics. Amsterdam/Philadelphia, Benjamins: $27-44$.

Ouhalla, Jamal (2009): "Variation and Change in Possessive Noun Phrases. The Evolution of the Analytic Type and Loss of the Synthetic Type". Brill's Annual of Afroasiatic Languages and Linguistics 1: 311-337.

Pereltsvaig, Asya (2006): "Head Movement in Hebrew Nominals. A Reply to Shlonsky". Lingua 116/8: A1-A40.

Pereltsvaig, Asya (2007): “The Universality of DP. A View from Russian”. Studia Linguistica 61/1: 59-94.

Ritter, Elizabeth (1988): “A Head Movement Approach to Construct-State Noun Phrases". Linguistics 26/6: 909-930.

Ritter, Elizabeth (1991): “Two Functional Categories in Noun Phrases. Evidence from Modern Hebrew". In: Rothstein, Susan (ed.): Perspectives on Phrase Structure. Heads and Licensing. San Diego/London, Academic Press: 37-62.

Shormani, Mohammed (2013): An Introduction to English Syntax. A Generative Approach. Saarbrücken: LAP.

Shormani, Mohammed (2014a): "Structural Ambiguity in Modern Standard Arabic: A Minimalist N-to-Spec Approach". Al-Qalam Journal 1: 1-35.

Shormani, Mohammed (2014b): "Clitic Construct State in Semitic. A Minimalist N-to-Spec Approach". Al-Qalam Journal 2: 1-47.

Shormani, Mohammed (2016): "Phase Theory. A Promising Approach to the Analysis of Semitic Construct State". Al-Qalam Journal 5: 1-44

Sichel, Ivy (2002): "Phrasal Movement in Hebrew Adjectives and Possessives". In: Alexiadou, Artemis et al. (eds.): Dimensions of Movement. From Features to Remnants. Amsterdam/Philadelphia, Benjamins: 297-339.

Sichel, Ivy (2003): "Phrasal Movement in Hebrew DPs". In: Lecarme, Jacqueline (ed.): Research in Afroasiatic Grammar II. Amsterdam/Philadelphia, Benjamins: 447-479. 
Siloni, Tal (1991): "Noun Raising and the Structure of Noun Phrases". In: Bobaljik, Jonathan/Bures, Tony (eds.): Papers from the Third Student Conference in Linguistics 1991. Cambridge, Department of Linguistics/Philosophy, MIT: 255-270. (= MIT Working papers in linguistics 14).

Siloni, Tal (1997): Noun Phrases and Nominalizations. The Syntax of DPs. Dordrecht: Kluwer.

Siloni, Tal (2001): "Construct States at the PF Interface". In: Pica, Pierre/Rooryck, Johan (eds.): Linguistic Variation Yearbook 1. Amserdam/Philadelphia, Benjamins: 229-266.

Siloni, Tal (2003): "Prosodic Case Checking Domain. The Case of Constructs". In: Lecarme, Jacqueline (ed.): Research in Afroasiatic Grammar II. Amsterdam/Philadelphia, Benjamins: 481-510.

Wintner, Shuly (2000): "Definiteness in the Hebrew Noun Phrase". Journal of Linguistics 36/2: 319-363.

Woidich, Manfred/Heinen-Nasr, Rabha (2004): Kullu tamān! An Introduction to Egyptian Colloquial Arabic. Cairo/New York, American University in Cairo Press.

Wright, William (1898): A Grammar of the Arabic Language. Cambridge: Cambridge University Press. 